\title{
ADVANCES IN ANESTHESIA
}

\section{Modern and Evolving Understanding of Cerebral Perfusion and Autoregulation}

\author{
Nathaniel H. Greene, $\mathrm{MD}^{\mathrm{a}}$, Lorri A. Lee, $\mathrm{MD}^{\mathrm{a}, \mathrm{b}, *}$
}

aDepartment of Anesthesiology and Pain Medicine, University of Washington, Seattle, WA 981956540 , USA; 'Department of Neurological Surgery, University of Washington, Seattle, WA 981956540 , USA

\section{Keywords}

- Cerebral perfusion - Cerebral blood flow - Autoregulation

- Lower limit of autoregulation • Cerebrovascular reactivity • Cerebral ischemia

- Beach chair position ${ }^{-}$Cerebral perfusion pressure

\section{Key Points}

- Significant changes in anesthetic management for optimizing cerebral perfusion have occurred over the past 5 to 10 years. Perhaps the most important of these changes has been a reinterpretation of older autoregulation studies that have resulted in raising the lower limit of autoregulation to approximately $70 \mathrm{~mm} \mathrm{Hg}$ to $80 \mathrm{~mm} \mathrm{Hg}$, and not the previously used $60 \mathrm{~mm} \mathrm{Hg}$.

- Tremendous variability in the lower limits of autoregulation exists among individuals. Using a percentage reduction below baseline blood pressure as a lower limit may result in better optimization of cerebral perfusion than using absolute blood pressure values.

- Other changes in practice for the general anesthesiologist include correcting blood pressure for height differences between the site of blood pressure measurement and the brain, particularly in the sitting position, to account for the hydrostatic gradient. Rare cases of severe brain damage have been reported that may be related to hypoperfusion in the beach chair position.

- Multiple physiologic and drug interactions that affect cerebral perfusion occur during every general anesthestic, and understanding the best way to optimize cerebral blood flow may potentially improve outcomes. Newer research on flow-metabolism coupling points to regional control of cerebral blood flow by the neurovascular unit, with glial cells playing a central role.

Disclosures: Dr Greene and Dr Lee report no financial disclosures.

${ }^{*}$ Corresponding author. Department of Anesthesiology and Pain Medicine, University of Washington, 1959 Northeast Pacific Street, Box 356540-BB 1469, Seattle, WA 98195-6540. E-mail address: lorlee@uw.edu 


\section{INTRODUCTION}

Defining the parameters that affect cerebral perfusion and understanding the pathophysiologic conditions that result in a supply and demand mismatch is of paramount concern for anesthesiologists. Stroke is one of the most devastating perioperative complications, and can occur with an incidence of $0.1 \%$ to $1.0 \%$ in patients undergoing noncardiac, non-neurological procedures, using national database statistics [1]. It is difficult to estimate what percentage of these perioperative strokes are related to embolic phenomena versus hypoperfusion, but hypoperfusion was strongly implicated as a causative factor in the multicenter randomized controlled trial Perioperative Ischemic Evaluation Study (POISE), in which patients receiving perioperative beta blockade had a twofold increased risk of stroke compared with patients who received placebo [2]. Retrospective single-institution studies have also found a significant relationship between perioperative stroke and intraoperative hypotension [3]. In contrast, a recent review of the literature noted that hypoperfusion was causative in only $6.6 \%$ of the 301 strokes identified [4]; yet, several studies have suggested that hypoperfusion may exacerbate the effect of microemboli. The indirect evidence suggests that "low" mean arterial pressure (MAP) may increase the risk of a perioperative stroke in certain high-risk individuals, but defining "low" for all patients and all procedures is problematic.

The goal of this article was to enhance the reader's understanding about factors that affect cerebral blood flow $(\mathrm{CBF})$, and to reexamine some misperceptions from earlier clinical studies on cerebral autoregulation and their impact on clinical practice. Rarer neurologic complications, such as ischemic optic neuropathy related to the prone and steep Trendelenburg positions, and severe brain damage in the sitting position, that highlight the potentially deleterious impact of patient position on cerebral perfusion are also discussed.

\section{FUNDAMENTALS OF CBF}

Humans have long been interested in cerebral perfusion and the brain as far back as $2800 \mathrm{BC}$, but it was not until the mid-1900s that the first techniques to measure CBF were developed by Kety and Schmidt (Fig. 1) [5-7]. We now have at least 18 different methods for measuring CBF, with newer tools of analysis, such as functional magnetic resonance imaging and positron emission computed tomography, that can demonstrate 3-dimensional images of CBF to a resolution of less than $1 \mathrm{~cm}[6]$. Widespread use of these newer techniques should improve our understanding of cerebral perfusion to better guide our clinical practice.

Inherent to understanding perfusion of the brain is first understanding the immense metabolic requirement of the brain. The brain makes up only $2 \%$ of the body weight, but receives as much as $15 \%$ to $20 \%$ of the cardiac output, approximately 50 to $60 \mathrm{~mL} / 100 \mathrm{~g}$ brain tissue/min, or 750 to $1000 \mathrm{~mL} / \mathrm{min}$ in an adult. It consumes as much as $20 \%$ of the total oxygen requirement at resting conditions at $3.3 \mathrm{~mL} / 100 \mathrm{~g}$ brain tissue/min $[5,6]$. Of the oxygen used, $40 \%$ is devoted to what is known as basal metabolism: homeostasis of 


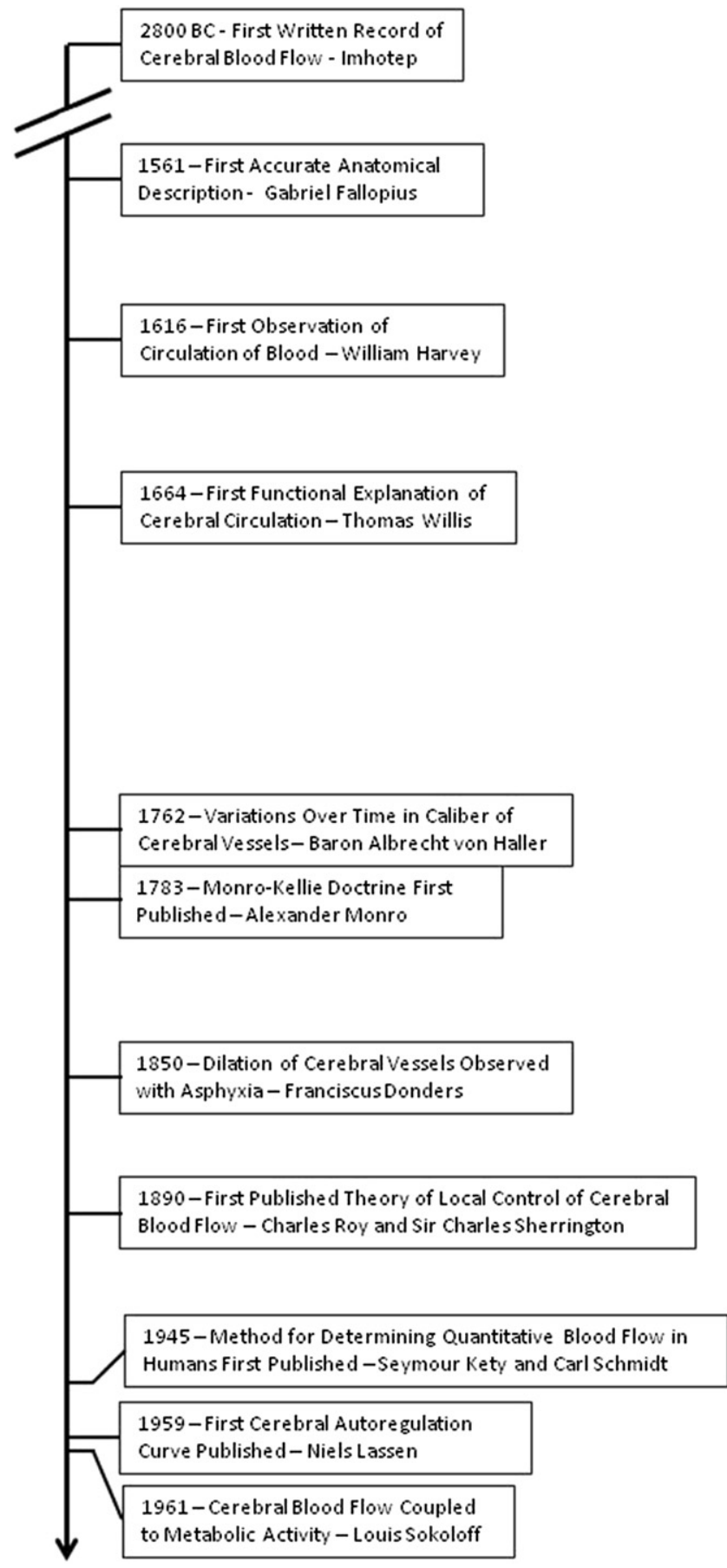

Fig. 1. Timeline of important milestones in the history of cerebral perfusion research. Data from Refs. [5-7]. 
the neuronal networks, providing adenosine triphosphate (ATP) to maintain ion gradients, and providing substrate for the central nervous system to communicate (ie, neurotransmitters, polypeptides, complex proteins). The other $60 \%$ is necessary for what is known as activation or functional metabolism: the energy required to support electrophysiologic function and to allow the neurons of the brain to communicate $[5,6]$. Because of its high metabolic activity and relatively low energy storage capacity, the brain is especially vulnerable to interruption of oxygen and substrate delivery.

\section{Circle of Willis}

In its most simple description, the circle of Willis is a continuous arterial circle that forms at the base of the brain by interconnections between branches of the left and right internal carotid arteries and the vertebrobasilar system. This circle is made because of formation of an anterior communicating artery that connects the left and right internal carotid systems between both anterior cerebral arteries, and the formation of posterior communicating arteries bilaterally that connect the carotid systems to the vertebrobasilar system between the middle cerebral arteries and the posterior cerebral arteries. Willis seemed to put it best after he made his anatomic discovery when he wrote "if by chance one or two should be stopt, there might easily be found another passage instead of them" [7]. The circle receives blood from 4 distinct sources that directly come from branches of the aorta with both internal carotid arteries being fed via the common carotid artery and both vertebral arteries being fed via the subclavian arteries. It should be noted that there is significant variance in the human population, with some studies suggesting that fewer than half of the population possess a complete circle of Willis.

\section{Control of $\mathrm{CBF}$}

There are several different mechanisms controlling CBF. The brain has adapted the ability to match CBF with metabolic rate through a variety of physiologic mechanisms, better known as flow-metabolism coupling. This coupling can occur regionally and is governed by several mechanisms that serve as the basis of how the brain is able to meet its unique demands. It is useful to separate these mechanisms into separate components with the understanding that they are still interrelated and can work either in concert or in opposition.

\section{Chemical/metabolic control}

The neurovascular unit. Current research indicates that the control of flowmetabolism coupling is primarily mediated through neurovascular units consisting of cerebral blood vessels, glial cells whose endfeet wrap around the vessels, and perivascular nerve fibers innervating the cerebral vessels and the glial cells (Box 1). The glial cells appear able to "sense" increased neuronal activity and release diffusible vasodilatory substances from the endfeet, thereby affecting CBF. More specifically, increased neuronal activity results in an increase in glial intracellular calcium, causing a release of ATP and glutamate [8]. ATP is involved in recruiting adjacent glial cells to respond as a unit via 


\section{Box 1: Control of CBF}

Control of CBF is centered around the neurovascular unit, which consists of the following:

- Perivascular nerve fibers innervating glial cells and blood vessels

- Glial cells with endfeet that wrap around cerebral vessels

- Cerebral vessels

Diffusible substances are secreted by the nerve fibers and glial cells, which affect CBF and increase connectivity of the neurovascular unit. The vascular endothelium also contributes to control of CBF. Glutamate affects both metabolism and CBF.

propagation of calcium waves. One of the many effects of glutamate is to stimulate production of nitric oxide (NO), which is a cerebral vasodilator and thought to be involved in the regulation of flow-metabolism coupling. Glutamate also activates glial cells via metabotropic glutamate receptors with subsequent calcium signaling and arachadonic acid formation. Arachadonic acid, or its lipid derivatives, serve as vasodilatory or vasoconstrictor substances released by the glial endfeet surrounding the cerebral blood vessels. NO, $\mathrm{K}+, \mathrm{H}+$, brain metabolites, such as adenosine and lactate, and $\mathrm{O}_{2}$ influence the direction of vascular tone [9]. $\mathrm{K}+$ and $\mathrm{H}+$ ions are produced by synaptic transmission, and increases in their concentrations stimulate cerebral vasodilation. Glutamate uptake by glial cells generates sodium waves that subsequently increase glucose uptake and metabolism. The increased lactate production from this metabolism is used by neurons as an energy substrate [8]. Glutamate increases connectivity of glial cells with neurons and capillaries (the neurovascular unit) as it affects both metabolism and CBF. The glial cells (astrocytes) play a vital role in local flow-metabolism coupling.

The perivascular nerve endings of cerebral vessels are also thought to be involved in flow-metabolism coupling via release of neurotransmitters, such as norepinephrine, acetylcholine, substance $\mathrm{P}$, somatostatin, cholecystokinin, vasoactive intestinal peptide, calcitonin gene-related peptide, epoxyeicosatrienoic acids (EETs), and others [10]. EETs are arachidonic acid metabolites, which are potent cerebral vasodilators and are also produced by astrocytes and the vascular endothelium. The source of innervation for this cerebral microvasculature (or "intrinsic innervation") is unknown in humans, but is thought to arise from the nucleus basalis, locus coeruleus, and raphe nucleus in animals [6]. The extrinsic innervation for flow-metabolism coupling is discussed later in this article.

Carbon dioxide. $\mathrm{CO}_{2}$, the main by-product of aerobic respiration, is a potent cerebral vasodilator and provides a very basic model of regulation by shifting blood toward more metabolically active tissues. A linear relationship exists between $\mathrm{CBF}$ and $\mathrm{CO}_{2}$ tension throughout normal physiologic values of $\mathrm{CO}_{2}$ (20-75 $\mathrm{mm} \mathrm{Hg}$ ), with an approximate $2 \%$ to $6 \%$ change in $\mathrm{CBF}$ per mm $\mathrm{Hg} \mathrm{CO}_{2}$ $[6,11,12]$. The effect of changes in $\mathrm{CO}_{2}$ on $\mathrm{CBF}$ depends on the underlying 
vascular tone and competing demands on $\mathrm{CBF}$, as there is a point of maximal vasodilation (and vasoconstriction) beyond which the vessel cannot further alter its diameter. For example, profound hypotension can greatly diminish $\mathrm{CO}_{2}$ reactivity because the cerebral vessels are maximally vasodilated. Similarly, hypercapnia can impede autoregulation for the same reasons.

The mechanism of $\mathrm{CO}_{2}$ reactivity is related to changes in the $\mathrm{pH}$ of the extracellular fluid surrounding the brain. Low-pH solutions topically applied to the brain surface cause vasodilation, whereas high- $\mathrm{pH}$ solutions cause vasoconstriction. $\mathrm{CO}_{2}$, unlike $\mathrm{H}+$ ions, readily diffuses across the blood brain barrier and cerebral endothelium [6]. Consequently, $\mathrm{CO}_{2}$ changes have a relatively quick effect on CBF, but metabolic acidosis has little immediate effect on CBF. Because the cerebrospinal fluid actively eliminates bicarbonate with prolonged hyperventilation and normalizes its $\mathrm{pH}$, effects on $\mathrm{CBF}$ typically revert to baseline within approximately 6 hours, even though the arterial partial pressure of $\mathrm{CO}_{2}\left(\mathrm{PaCO}_{2}\right)$ may remain low. Thus, acute correction of $\mathrm{PaCO}_{2}$ after prolonged hyperventilation can lead to pronounced increases in $\mathrm{CBF}$, which may have deleterious effects on patients with raised intracranial pressure (ICP) [6].

The change in vascular tone caused by $\mathrm{CO}_{2}$ is partially mediated by $\mathrm{NO}$, as inhibitors of $\mathrm{NO}$ synthase will diminish the vasodilatory response to hypercapnia. NO modulation of cerebrovascular tone occurs through combined activation of ATP-sensitive and calcium-activated potassium channels in animal studies [13]. Indomethacin, an inhibitor of cyclooxygenase and prostaglandin formation, will partially inhibit the vasodilatory response to increasing $\mathrm{CO}_{2}$ concentrations in humans. Experimental studies in animals show that application of prostaglandin E2 (PGE2) after indomethacin administration will restore the cerebrovascular reactivity to baseline, as PGE2 is thought to stimulate production of endothelial NO synthase [14]. Studying these mechanisms at this level of complexity has been difficult, as they have been shown to differ depending on the animal studied.

$\mathrm{PaO}_{2}$, arterial $\mathrm{O}_{2}$ content, and rheology. Oxygen $\left(\mathrm{O}_{2}\right)$, also exhibits regulatory capacity, as $\mathrm{CBF}$ increases when $\mathrm{O}_{2}$ levels start to drop below $60 \mathrm{~mm} \mathrm{Hg}$ in humans [15]. Early studies in normocapnic rats showed that CBF significantly increased at $\mathrm{PaO}_{2}$ levels as high as $85 \mathrm{~mm} \mathrm{Hg}$, but that marked increases up to $500 \%$ of baseline CBF occurred within 1 to 2 minutes at a $\mathrm{PaO}_{2}$ of $25 \mathrm{~mm} \mathrm{Hg}$ [16]. NO synthase inhibitors given to humans partially blocked this response, suggesting that it is partially regulated by $\mathrm{NO}$ [17]. Chemoreceptors in the periphery and neuraxis, and hyperpolarization of vascular smooth muscle via ATP-dependent potassium channels, may also contribute to hypoxia-induced vasodilation [6].

Hypoxemia increases $\mathrm{CBF}$ to a greater degree than hemodilution, at the same arterial $\mathrm{O}_{2}$ content $\left(\mathrm{CaO}_{2}\right)$ [18]. Hemodilution has been well documented in animal and human studies to increase $\mathrm{CBF}$ and raise the lower limit of autoregulation (LLA) $[18,19]$. Both the decreased viscosity with improved rheology, and reduced $\mathrm{CaO}_{2}$ are responsible for the increase in CBF with hemodilution, based on studies in animals [20]. Although NO is involved in 
cerebral vasodilation with reduced $\mathrm{CaO}_{2}$ from hypoxemia, it does not appear to contribute to increased CBF with reduced viscosity [18].

Temperature. Temperature-induced changes in $\mathrm{CBF}$ are a reflection of changes in the cerebral metabolic rate of $\mathrm{O}_{2}\left(\mathrm{CMRO}_{2}\right)$. As a patient's temperature drops, there is a corresponding drop in $\mathrm{CMRO}_{2}$ from both basal and functional metabolism, estimated to be approximately $7 \%$ for each $1^{\circ} \mathrm{C}$ between $37^{\circ} \mathrm{C}$ and $27^{\circ} \mathrm{C}$ [5]. Isoelectric electroencephalogram (EEG) occurs at temperatures of 18 to $20^{\circ} \mathrm{C}$. Pharmacologic suppression, which only affects functional metabolism, is synergistic with hypothermic suppression until EEG silence. At that point, $\mathrm{CMRO}_{2}$ can be reduced only by further drops in temperature [6]. Numerous smaller studies have documented the improved survival and outcomes using mild to moderate hypothermia in traumatic brain injury (TBI) and other pathologic states, and the deleterious effects of hyperthermia. Larger randomized controlled trials of hypothermia in traumatic brain injury and during clipping of cerebral aneursyms have not demonstrated a beneficial effect for all patients $[21,22]$. Hypothermia seems to be neuroprotective during vulnerable periods of cerebral ischemia in successfully resuscitated cardiac arrest patients [23].

One of the few studies in humans with hyperthermia and controlled ventilation showed that increasing temperatures to $41.8^{\circ} \mathrm{C}$ with propofol anesthesia decreased $\mathrm{O}_{2}$ extraction by 1.6 -fold and increased middle cerebral artery blood flow velocity by 1.5 -fold, with partial impairment of autoregulation [24]. It was suggested that the decreased $\mathrm{O}_{2}$ extraction was a consequence of a similar increase in $\mathrm{CBF}$, and that $\mathrm{CMRO}_{2}$ may actually have been stable. In animals, $\mathrm{CMRO}_{2}$ increases up to $42^{\circ} \mathrm{C}$, and then falls to baseline values or lower at $43^{\circ} \mathrm{C}$, presumably because of metabolic dysfunction and impending cell death. In contrast to anesthetized subjects with controlled ventilation, research in awake, spontaneously ventilating humans and animals revealed that CBF decreased with hyperthermia, largely because of an associated increase in ventilation and reduced $\mathrm{PaCO}_{2}$ (Box 2) [25].

Neurogenic control

In addition to the extensive network of perivascular nerve endings associated with the neurovascular unit discussed previously, neurogenic control of CBF

\section{Box 2: Physiologic parameters affecting CBF}

- Carbon dioxide

- $\mathrm{PaO}_{2} /$ arterial $\mathrm{O}_{2}$ content

- Temperature

- Viscosity/rheology

- Sympathetic/Parasympathetic stimulation

- Myogenic control/autoregulation

Anemia increases $\mathrm{CBF}$ by its effect on viscosity/rheology and arterial $\mathrm{O}_{2}$ content. 
is also mediated via sympathetic (adrenergic), parasympathetic (cholinergic), and sensory neurons that innervate vessels outside of the brain tissue, sometimes referred to as the "extrinsic innervation" [26]. The extrinsic system of neurogenic control of $\mathrm{CBF}$ is thought to exert its most pronounced effect on the large cerebral arteries. The sympathetic nervous system associated with the superior cervical ganglion influences vascular tone to maintain blood pressure below the upper limit of autoregulation [27]. Sympathetic stimulation can alter the autoregulatory curve and push it to the right, possibly providing a protective effect during periods of acute hypertension [28,29]. Intense stimulation of the sympathetic nervous system has been shown to cause a significant decrease in CBF, whereas local blockade of the sympathetic nervous system can provide a significant increase in CBF $[28,30]$. In a study using baboons, in which autoregulation was intact to $35 \%$ of baseline blood pressure when hypotension was drug induced, autoregulation was intact to only $65 \%$ of baseline blood pressure when hypotension was induced by controlled hemorrhage, suggesting that activation of the sympathetic nervous system during hemorrhage contributed to a higher LLA [31]. The role of lower cardiac output in this scenario was not elucidated, but numerous studies suggest that acute hypovolemia may narrow the range of autoregulatory capacity and raise the LLA via activation of the sympathetic nervous system.

The parasympathetic nervous system is associated with the sphenopalatine and otic ganglia and is more functional during disease or injury states, such as Alzheimer disease, with decreased cholinergic innervation [26]. However, both the cholinergic and adrenergic nerves are thought to be involved in exerciseinduced changes in $\mathrm{CBF}$ and metabolism. Sensory neurons work through the trigeminal ganglion and are important for pain sensation [26]. The discovery of trigeminal neurons in mediating migraine pain via the vasodilator, calcitonin gene-related peptide (CGRP), has led to the development of triptan drugs that inhibit release of CGRP presynaptically and cause cerebral vasoconstriction.

\section{Myogenic control/autoregulation}

In the healthy resting human, $\mathrm{CBF}$ is kept constant over a wide range of cerebral perfusion pressures $(\mathrm{CPP})$ via cerebral vasoconstriction and vasodilation. This concept is known as autoregulation and seems to exist in humans, as well as in other vertebrates. It is a process whereby changes in CPP cause changes in cerebrovascular resistance to maintain a constant CBF. Cerebral autoregulation protects the brain from hypoxia at low CPP, and against hyperemia, capillary leakage, and vasogenic edema at high CPP. As the cerebral vessels have limits to how wide they can dilate and how small they can constrict, there are limits to this autoregulatory capacity, and if exceeded, blood flow becomes pressure passive and is subject to changes in systemic blood pressure. The LLA is the CPP when there is maximal cerebral vasodilation. The upper limit of autoregulation (ULA) is the CPP where there is maximal cerebral vasoconstriction (Fig. 2). Autoregulatory ranges vary greatly among individuals and within an individual depending on other influences on vascular tone (eg, $\mathrm{PaCO}_{2}$, hemoglobin concentration, anesthetic agents). Older 
Factors Decreasing Cerebral Blood Flow

Factors Increasing Cerebral Blood Flow

\begin{tabular}{|c|c|c|c|c|c|}
\hline & CBF & $\mathrm{CMRO}_{2}$ & & CBF & $\mathrm{CMRO}_{2}$ \\
\hline Vasoactive Drugs & & & \multirow{2}{*}{\multicolumn{2}{|c|}{$\begin{array}{l}\text { Vasoactive Drugs } \\
\text { Hypotensive Agents }\end{array}$}} & \\
\hline \multicolumn{3}{|l|}{ Hypotensive Agents } & & & \multirow{4}{*}{$\begin{array}{l}\uparrow / 0 \\
\downarrow / 0\end{array}$} \\
\hline$\beta$ Blockers & $\downarrow / 0$ & $\downarrow / 0$ & Calcium Channel Blockers & \multirow{3}{*}{$\begin{array}{c}\uparrow / 0 \\
\downarrow / 0 / \uparrow\end{array}$} & \\
\hline$\alpha 2$ Agonist & $\downarrow$ & $\downarrow / 0$ & Nitric Oxide Donors & & \\
\hline Nitric Oxide Donors & $\downarrow / 0 / \uparrow$ & $\downarrow / 0$ & & & \\
\hline \multicolumn{3}{|c|}{ Vasopressors/Inotropes/Chronotropes } & \multicolumn{3}{|l|}{ Vasopressors/Inotropes/Chronotropes } \\
\hline$\alpha 1$ Agonist & $\downarrow / 0$ & 0 & $\beta$ Agonist & $\uparrow$ & $\uparrow$ \\
\hline Dopamine (high dose) & $\downarrow$ & 0 & $\beta$ Agonist (BBB open) & 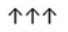 & 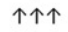 \\
\hline Norepinephrine & $\downarrow / 0$ & $0 / \uparrow$ & Dopamine (low dose) & $\uparrow \uparrow$ & 0 \\
\hline \multirow[t]{2}{*}{ Vasopressin } & \multirow[t]{2}{*}{0} & \multirow[t]{2}{*}{0} & Norepinephrine (BBB open) & $\uparrow$ & $\uparrow$ \\
\hline & & & Epinephrine & $\uparrow$ & $\uparrow$ \\
\hline Anesthetic Drugs & & & \multirow{2}{*}{ Anesthetic Drugs } & 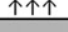 & 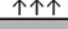 \\
\hline \multirow{2}{*}{\multicolumn{3}{|c|}{ Intravenous Agents }} & & & \\
\hline $\begin{array}{l}\text { Intravenous Agents } \\
\text { Barbiturates }\end{array}$ & & & \multirow{2}{*}{$\begin{array}{l}\text { Intravenous Agents } \\
\text { Ketamine }\end{array}$} & \multirow{3}{*}{$\begin{array}{l}\uparrow \uparrow \\
\downarrow / 0\end{array}$} & \multirow{3}{*}{$\begin{array}{l}0 / \uparrow \\
\downarrow / 0\end{array}$} \\
\hline $\begin{array}{l}\text { Barbiturates } \\
\text { Etomidate }\end{array}$ & $\begin{array}{l}\downarrow \downarrow \\
\downarrow \downarrow\end{array}$ & $\downarrow \downarrow$ & & & \\
\hline Propofol & $\begin{array}{l}\downarrow \downarrow \\
\downarrow \downarrow\end{array}$ & $\begin{array}{l}\downarrow \downarrow \\
\downarrow \downarrow\end{array}$ & \multirow{3}{*}{ Ketamine ( $w /$ other anesthetics) } & & \\
\hline Benzodiazepines & $\downarrow$ & $\downarrow$ & & & \\
\hline Synthetic Opioids & 0 & $\downarrow / 0$ & & & \\
\hline \multicolumn{3}{|l|}{ Volatile Agents } & \multicolumn{2}{|l|}{ Volatile Agents } & \\
\hline Xenon & $\downarrow($ Gray $) / \uparrow($ White $)$ & $\downarrow$ & Nitrous Oxide & 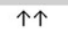 & $0 / \uparrow$ \\
\hline Isoflurane $(0.5-1 \mathrm{MAC})$ & 0 & $\downarrow \downarrow$ & Isoflurane (2 MAC) & 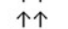 & $\downarrow \downarrow$ \\
\hline Sevoflurane (0.5 - $1 \mathrm{MAC})$ & $\downarrow / 0$ & $\downarrow / \downarrow \downarrow$ & Sevoflurane (2 MAC) & 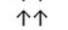 & $\downarrow / \downarrow \downarrow$ \\
\hline Desflurane (0.5 -1 MAC) & $\downarrow$ & $\downarrow \downarrow$ & Desflurane (2 MAC) & 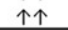 & $\downarrow \downarrow$ \\
\hline \multicolumn{3}{|l|}{ Physiologic Parameters } & \multicolumn{2}{|l|}{ Physiologic Parameters } & \\
\hline $\mathrm{PaCO}_{2}<40 \mathrm{~mm} \mathrm{Hg}$ & $\downarrow \downarrow$ & 0 & \multirow{4}{*}{$\begin{array}{c}\text { Temperature }>37^{\circ} \mathrm{C} \\
\mathrm{PaO}_{2}<60 \mathrm{~mm} \mathrm{Hg} \\
\mathrm{PaCO}_{2}>40 \mathrm{~mm} \mathrm{Hg} \\
\text { Anemia }\end{array}$} & $\uparrow$ & $\uparrow$ \\
\hline $\mathrm{PaO}_{2}>300 \mathrm{~mm} \mathrm{Hg}$ & $0 / \downarrow$ & 0 & & $\uparrow \uparrow$ & 0 \\
\hline Temperature $<37^{\circ} \mathrm{C}$ & $\downarrow$ & $\downarrow$ & & 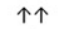 & 0 \\
\hline Viscosity ( $\uparrow)$ & $\downarrow$ & 0 & & $\uparrow$ & 0 \\
\hline
\end{tabular}

$* *$ It should be noted these are isolated effects, and that the effect of simultaneous factors may be additive or they may diminish or completely abolish an effect on CBF.

Fig. 2. Pharmacology of CBF. Drugs and physiologic parameters that affect $C B F$ and autoregulation. *, ** 
texts have cited limits of autoregulation in healthy patients under normal physiologic conditions at a CPP of $50 \mathrm{~mm} \mathrm{Hg}$ (approximate MAP of $60 \mathrm{~mm} \mathrm{Hg}$ ) at the LLA and $140 \mathrm{~mm} \mathrm{Hg}$ (approximate MAP $150 \mathrm{~mm} \mathrm{Hg}$ ) at the ULA. Reinterpreting these older studies for clinical translation has led to a revision of the LLA to a MAP of $70 \mathrm{~mm} \mathrm{Hg}$ in healthy adults, (see section Lower Limit of Autoregulation that follows) [6].

The process by which autoregulation occurs is unknown but is relatively slow, taking approximately 2 or more minutes for CBF to adjust to baseline values after an acute drop in MAP. Autonomic innervations of the central nervous system and NO may have contributory roles to the mechanism of autoregulation [32]. Increases in transmural pressure are known to induce an endothelium-derived factor that induces smooth muscle depolarization. This depolarization causes a conformational change in the actin-myosin complex of the smooth muscle cells within seconds and results in vasoconstriction. Recent research has detected mechanoreceptors within the smooth muscle cells themselves. Depolarization of these nonselective mechanosensitive ion channels results in an influx of $\mathrm{Ca}++$ and smooth muscle constriction. Increased flow velocity exerts increased shear stress and can cause vasoconstriction independent of transmural pressure [26].

\section{LOWER LIMIT OF AUTOREGULATION}

Historical interpretation of the LLA for cerebral ischemia

The LLA commonly refers to the MAP (or CPP) on the CBF versus MAP (or CPP) autoregulatory curve in which the cerebral blood vessels are maximally dilated, and in which CBF becomes pressure passive if MAP (or CPP) is further lowered (Fig. 3). In the past, the LLA has erroneously been thought of as an absolute number for all patients. Instead, it varies among and within individuals, and depends on the state of multiple other physiologic parameters and pharmacologic agents that may influence cerebral sympathetic tone and limit the extent of autoregulatory capacity. It has received great attention because of the implications for blood pressure management under anesthesia in normal and diseased states. Because intact neurologic function cannot be assessed, even with today's best technology, under moderate to deep sedation or general anesthesia, anesthesiologists have always been interested in defining the lower limit of "safe" blood pressure whereby adequate cerebral perfusion is ensured if blood pressure is maintained above this lower limit. Although one could always keep the MAP, no lower than baseline values to ensure adequate CPP, this practice may have the unintended consequences of increased bleeding in some procedures, and could promote harmful side effects of increased blood transfusion, or other fluid or vasoactive medication administration.

Blood pressures lower than a predetermined LLA do not necessarily result in immediate and irreparable brain damage. The duration and extent of the decrease in CPP below the LLA are important, with less dramatic decreases being tolerated for longer duration. Awake healthy subjects developed symptoms of cerebral ischemia at CBF of 24 to $38 \mathrm{~mL} / 100 \mathrm{~g} / \mathrm{min}$ [33]. Although most studies 


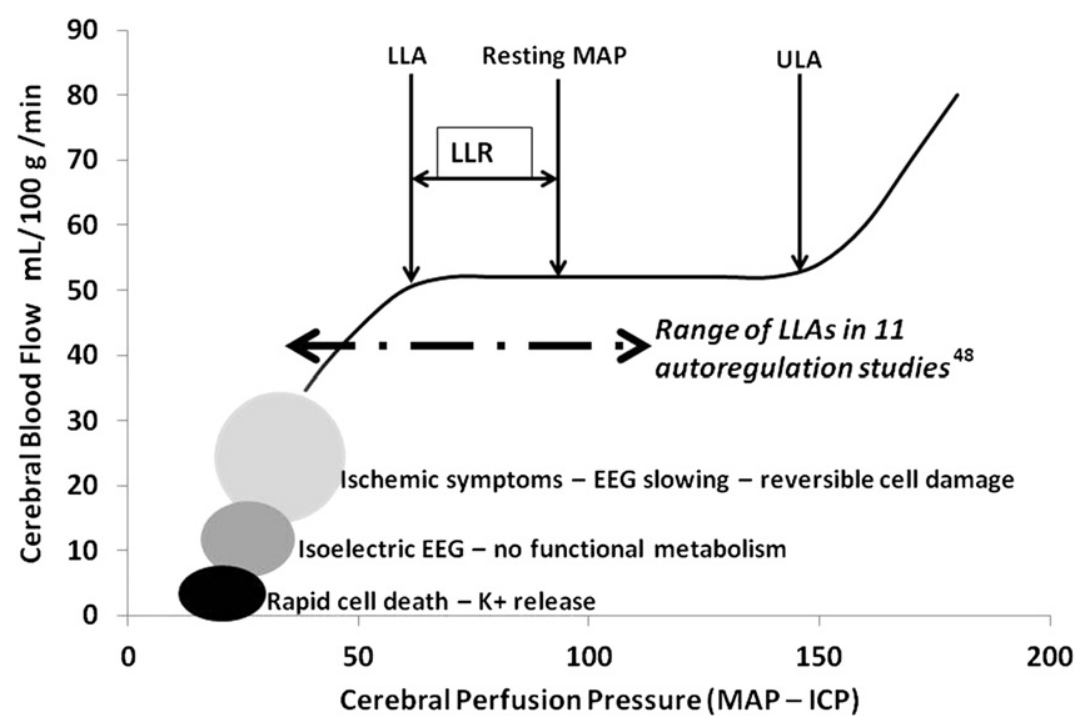

Fig. 3. Autoregulation curve. The cerebral vasculature maintains a stable CBF over a wide range of CPP (typically CPP 60-140 or MAP 70-150 mm Hg). The lower end of the autoregulatory range is the LLA, where there is maximal cerebral vasodilation. The ULA is when there is maximal cerebral vasoconstriction. The area between the baseline MAP and the LLA is known as the lower limit reserve (LLR). Symptoms and signs (EEG slowing) of cerebral ischemia occur at approximately 24 to $38 \mathrm{~mL} / 100 \mathrm{~g} / \mathrm{min} \mathrm{CBF}$ and neuronal damage is still reversible. Functional metabolism ceases between 15 and $6 \mathrm{~mL} / 100 \mathrm{~g} / \mathrm{min}$ with an isoelectric EEG, and neurons will eventually die. Destruction of cell integrity occurs at approximately $\mathrm{CBF}<6 \mathrm{~mL} /$ $100 \mathrm{~g} / \mathrm{min}$ and rapid cell death ensues. The lower the CBF at ischemic levels, the shorter the duration allowable before irreversible neuronal damage. The dashed-dotted line represents the range of LLAs from 11 autoregulation studies in awake humans. (Data from Drummond JC. The lower limit of autoregulation: time to revise our thinking? Anesthesiology 1997;86(6):1431-3.)

in anesthetized humans and primates report that EEG or evoked potential changes do not occur until CBF declines to approximately $20 \mathrm{~mL} / 100 \mathrm{~g} / \mathrm{min}$ [34,35], preexisting neuronal injury may raise that threshold to as high as $39 \mathrm{~mL} / 100 \mathrm{~g} / \mathrm{min}$ [36]. Other factors that may reduce $\mathrm{O}_{2}$ delivery, such as anemia or low $\mathrm{PaO}_{2}$, or increase in $\mathrm{CMRO}_{2}$, may raise the $\mathrm{CBF}$ threshold in which ischemia develops. In anesthetized primates at a $\mathrm{CBF}$ of $15 \mathrm{~mL} / 100 \mathrm{~g} / \mathrm{min}$, functional metabolism ceases as demonstrated by an isoelectric EEG, and below $6 \mathrm{~mL} / 100 \mathrm{~g} / \mathrm{min}$, cell integrity is potentially irreversibly threatened [37]. Although irreversible brain damage will not occur if a patient's MAP briefly drops below his or her LLA, keeping the MAP above the LLA should provide some margin for error, assuming other physiologic conditions are normal.

Determination of the LLA for a population is problematic. As noted previously, careful reconsideration of the early studies on autoregulation has resulted in a revised recommendation to maintain $\mathrm{MAP}$ at $70 \mathrm{~mm} \mathrm{Hg}$ or higher in major anesthesia texts [6]. This number was derived from the mean LLA of the studies 
examined by Drummond in his brief review [38]. It has always been standard practice in articles to list the mean values with the standard deviations (SDs). As an unintended consequence of this practice, the focus of the data lies with the mean values, which when used as a cutoff point will not encompass a large proportion of the subjects and their variability. Using the mean value plus 1 SD should encompass $68.2 \%$ of the values in a normally distributed bellshaped curve; the mean value plus $2 \mathrm{SDs}$, 95.9\%; and the mean value plus $3 \mathrm{SDs}, 99.7 \%$. Drummond attempted to rectify this misconstrued extrapolation of autoregulation studies by denoting the ranges of the LLAs within multiple autoregulation studies in awake patients, instead of using only the mean LLAs (Box 3) [38]. The range of mean LLAs was 57 to $91 \mathrm{~mm} \mathrm{Hg}$, with 5 of these 7 studies obtaining a mean LLA of $70 \mathrm{~mm} \mathrm{Hg}$ or higher. Moreover, if the ranges of LLAs within studies were examined, every study had the upper range of LLA above $70 \mathrm{~mm} \mathrm{Hg}$, and 4 of the 7 studies had the upper range of LLA at $100 \mathrm{~mm}$ $\mathrm{Hg}$ or higher. Notably, these autoregulation studies were performed in awake individuals, and presumably $\mathrm{CMRO}_{2}$ will be reduced in patients under general anesthesia. Further, many of our anesthetic agents are cerebral vasodilators and may provide another "buffer" to preventing inadequate cerebral perfusion; yet, unfavorable physiologic conditions, which lower CBF or raise the LLA, such as hypocapnia and anemia, may also be present, which may decrease the margin for "error" or harm on lowering the blood pressure.

\section{Defining LLA as a percentage reduction of MAP below baseline}

Drummond [38] advocated revisiting what we considered a "safe" LLA by using percentage reductions from baseline resting MAPs as a way to address the extreme interpatient variability in absolute LLA values. This practice is standard management in neuroanesthesia. Strandgaard [39] demonstrated in 1976 that awake normotensive subjects' mean LLA was approximately $74 \% \pm 12 \%$ of baseline, or a $26 \% \pm 12 \%$ reduction from baseline MAP. In patients with uncontrolled hypertension, the LLA was $79 \% \pm 10 \%$ of baseline MAP, or a $21 \% \pm$ $10 \%$ reduction from baseline MAP (see Box 3). Ischemic symptoms developed in both groups at approximately 55\% of baseline MAP, or a 45\% reduction.

These percent reductions for LLAs are consistent with the recent nested casecontrol study of Bijker and colleagues [3], who studied more than 48,000 patients retrospectively and identified 42 patients with an ischemic stroke within 10 days of surgery. These stroke cases were matched by age and type of surgery to 252 control patients and adjusted for potential confounding factors. They found a statistically significant association with the duration that the intraoperative MAP was

\section{Box 3: The lower limit of autoregulation}

After reexamination of multiple autoregulation studies, the LLA has been shifted upward to $70 \mathrm{~mm} \mathrm{Hg}$ in major texts.

This LLA will not encompass all patients, as there is tremendous interindividual variability in the LLA. Using a percent reduction from the baseline blood pressure as a method to estimate the LLA may accommodate this variability. 
decreased more than $30 \%$ from baseline and the occurrence of an ischemic stroke within 10 days after surgery [3]; however, half of these 42 patients with stroke had carotid endarterectomy surgery and 6 had surgery for tumors of the head and neck. Only 13 cases of stroke occurred after general surgical procedures.

In sharp contrast to the previously mentioned work on the LLA are the multiple studies from Sharrock and colleagues [40] demonstrating that MAPs of 50 to $55 \mathrm{~mm} \mathrm{Hg}$ are well tolerated by patients undergoing hip surgery in the lateral decubitus position using epidural local anesthetic infusions and intravenous epinephrine infusions. Early studies by this group without the epinephrine infusions had a "number of patients" with symptoms of cerebral ischemia, such as yawning, nausea, or drowsiness associated with cardiac indices lower than $1.8 \mathrm{~L} / \mathrm{min} / \mathrm{m}^{2}$. When the low-dose epinephrine infusions were added, cardiac output was increased with a similar MAP, and the symptoms of cerebral ischemia abated. These studies imply that cardiac output either directly or indirectly affects CBF, as CPP reportedly stayed constant.

\section{EFFECT OF SIMULTANEOUS FACTORS ON CBF: CLINICAL SCENARIOS}

Patient condition and anesthetic management impose multiple simultaneous factors that can affect $\mathrm{CBF}, \mathrm{CMRO}_{2}$, cerebrovascular reactivity, and autoregulation. Consideration of the underlying vascular tone and the severity of the physiologic condition and dosage of anesthetic should be made when assessing adequacy of cerebral perfusion (Box 4). This section provides several examples of the effects of multiple simultaneous factors on CBF.

Effect of carbon dioxide on autoregulation in awake and anesthetized subjects

Baseline autoregulation studies are typically performed at $\mathrm{PaCO}_{2}$ of approximately $40 \mathrm{~mm} \mathrm{Hg}$, and they demonstrate the range of blood pressure over which an individual can alter their cerebrovascular tone to maintain a constant CBF. Because $\mathrm{CO}_{2}$ also alters the vascular tone, at higher $\mathrm{PaCO}_{2}$ levels it will impose underlying vasodilation and alter the ability of the vasculature to further dilate with low MAP. Aaslid and colleagues [41] used transcranial Doppler and insonation of the middle cerebral artery in awake humans to demonstrate that the fastest rate of regulation of CBF velocity using thigh cuff deflation occurred with hypocapnia $\left(\mathrm{PaCO}_{2}\right.$ of $22.2 \mathrm{~mm} \mathrm{Hg}$, highest tone) and the slowest with hypercapnia $\left(\mathrm{PaCO}_{2}\right.$ of $46.9 \mathrm{~mm} \mathrm{Hg}$, lowest tone) [41]. At even higher $\mathrm{PaCO}_{2}$ levels $(50-61 \mathrm{~mm} \mathrm{Hg})$ under remifentanil plus sevoflurane anesthesia (1.0\%-1.1\% end tidal concentration), McCulloch and colleagues [42], using transcranial Doppler, demonstrated that autoregulation

\section{Box 4: Underlying vascular tone affects response on CBF}

The effect of any drug or change in physiology on the CBF will depend on the underlying cerebrovascular tone. 
was significantly impaired in healthy subjects. For propofol $(140 \mu \mathrm{g} / \mathrm{kg} / \mathrm{min})$ anesthesia, the level at which significant impairment of autoregulation occurred was slightly higher, $\mathrm{PaCO}_{2}$ of 54 to $66 \mathrm{~mm} \mathrm{Hg}$. These findings are consistent with the concept of underlying vascular tone, in this case vasodilation, affecting the ability of the cerebral vessels to vasoconstrict. Moreover, McCulloch and colleagues [42] found that $\mathrm{CO}_{2}$ reactivity was greater at an MAP of $100 \mathrm{~mm}$ $\mathrm{Hg}$ than at $80 \mathrm{~mm} \mathrm{Hg}$, for both sevoflurane and propofol, presumably because the underlying vasoconstriction at higher MAP allowed the $\mathrm{CO}_{2}$ to exert a greater effect on vasodilation. At lower MAP with hypercapnia, the ability to vasodilate fully will be diminished compared with isocapnic conditions, and the LLA will be shifted to the right, or increased.

\section{Effect of hypotension on carbon dioxide reactivity}

Harper and Glass [43] demonstrated the effect of varying levels of hypotension on $\mathrm{CO}_{2}$ reactivity in dogs anesthetized with nitrous oxide and oxygen and intermittent small doses of thiopentone (Fig. 4). With severe hypotension

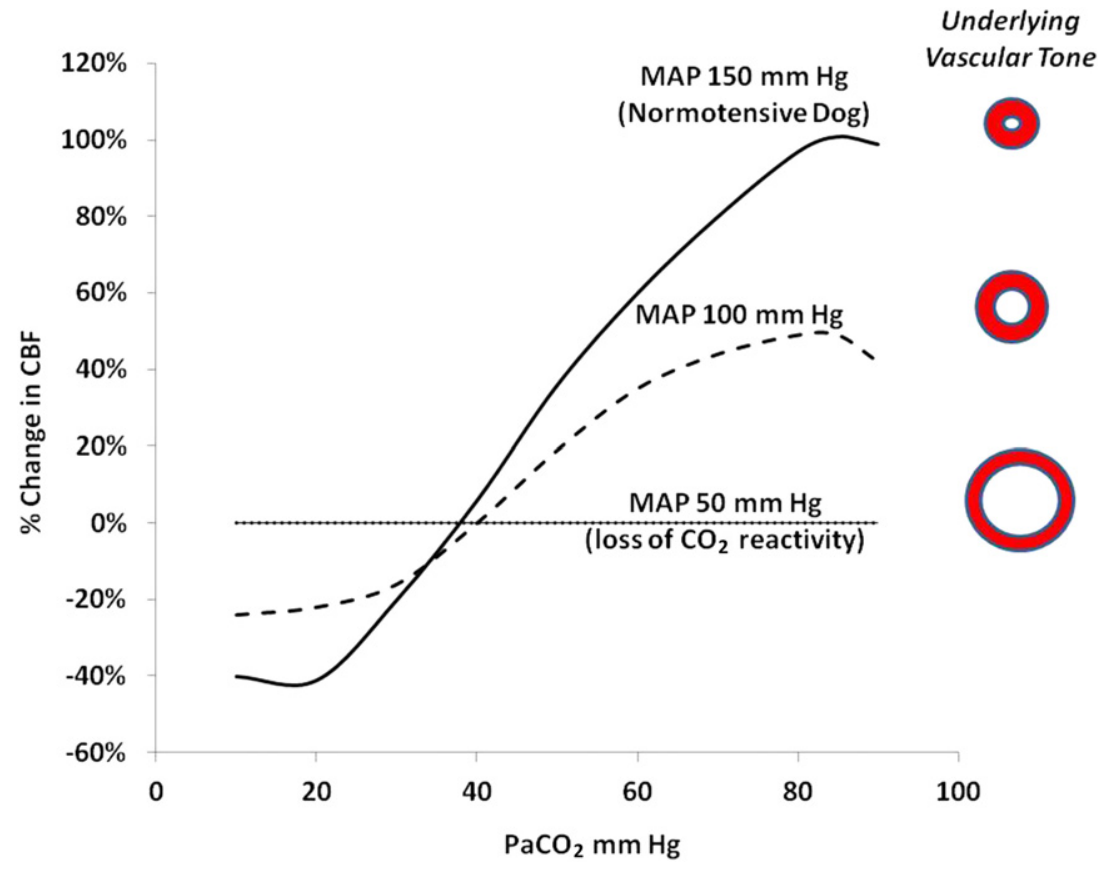

Fig. 4. The effect of hypotension on $\mathrm{CO}_{2}$ reactivity in dogs. In normothermic $\left(\mathrm{T} 38^{\circ} \mathrm{C}\right)$, normotensive (MAP $150 \mathrm{~mm} \mathrm{Hg}$ ) dogs, the effect of $\mathrm{CO}_{2}$ on $\mathrm{CBF}$ was almost linear between $\mathrm{PaCO}_{2}$ 20 to $80 \mathrm{~mm} \mathrm{Hg}$. The slope of the $\mathrm{CO}_{2}$ reactivity curve decreases with moderate hypotension (MAP $100 \mathrm{~mm} \mathrm{Hg}$ ). $\mathrm{CO}_{2}$ reactivity is abolished with severe hypotension at a MAP of $50 \mathrm{~mm}$ $\mathrm{Hg}$ because of the maximal underlying cerebrovascular dilation caused by the hypotension. (Adapted from Harper AM, Glass HI. Effect of alterations in the arterial carbon dioxide tension on the blood flow through the cerebral cortex at normal and low arterial blood pressures. J Neurol Neurosurg Psychiatry 1965;28:449.) 
(via exsanguination) at a MAP of $50 \mathrm{~mm} \mathrm{Hg}$ (normotensive MAP $150 \mathrm{~mm}$ $\mathrm{Hg}), \mathrm{CO}_{2}$ reactivity is abolished in the dog. The cerebral vasculature is presumably maximally vasodilated and cannot respond further to increasing $\mathrm{PaCO}_{2}$. The clinical implication is that during severe hypotension, raising the $\mathrm{PaCO}_{2}$ level will not necessarily increase CBF.

\section{Effect of temperature and propofol dose on $\mathrm{CBF}$ and $\mathrm{CMRO}_{2}$}

Hypothermia $\left(35^{\circ} \mathrm{C}\right)$ and increasing propofol doses in monkeys have additive effects on $\mathrm{CMRO}_{2}$ and $\mathrm{CBF}$ reduction (Fig. 5) [44]. No significant interaction was found between temperature and propofol dose. These findings are consistent with other data suggesting that initial reductions in temperature exert a greater effect on basal metabolism, whereas anesthetic drugs exert their effect on functional metabolism. These additive reductions in $\mathrm{CMRO}_{2}$ and $\mathrm{CBF}$, with good flow-metabolism coupling, may be clinically useful in situations with elevated ICP.

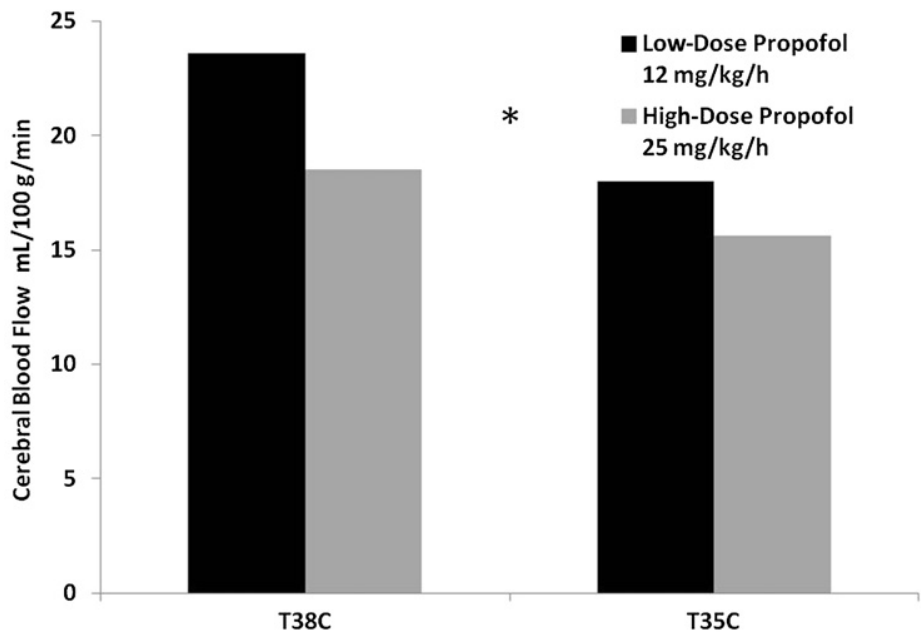

Fig. 5. The additive effects of mild hypothermia and propofol on $\mathrm{CBF}$ in dogs. Both propofol and mild hypothermia $\left(35^{\circ} \mathrm{C}\right)$ decrease $\mathrm{CBF}$ and $\mathrm{CMRO}_{2}$ with good flow-metabolism coupling in normothermic, isocapnic dogs. The effects are additive (no interaction effect), as mild hypothermia is thought to predominately affect basal metabolism and propofol affects functional metabolism. ${ }^{*} P<.05$ comparing normothermic with hypothermic propofol groups. (Adapted from Ouchi T, Ochiai R, Takeda J, et al. Combined effects of propofol and mild hypothermia on cerebral metabolism and blood flow in rhesus monkey: a positron emission tomography study. J Anesth 2006:20:208.)

\section{Effect of anemia on CBF and autoregulation}

Anemia increases $\mathrm{CBF}$ by 2 mechanisms, as discussed previously: reduced $\mathrm{CaO}_{2}$ and reduced viscosity. Because the cerebral vessels are dilated with anemia, the LLA is shifted to the right. The ability of the cerebral vessels to 
dilate is limited because of the preexisting dilation caused by the anemia. Maruyama and colleagues [45] demonstrated that increasing severity of anemia (hematocrit values of 40\%, 20\%, and 5\%) in dogs progressively raises the CBF at a MAP of $100 \mathrm{~mm} \mathrm{Hg}$, such that CBF with a hematocrit of $20 \%$ is 1.7 -fold that of baseline hematocrit of $40 \%$, and CBF with a hematocrit of 5\% is 3.0-fold higher than baseline. Additionally, the range of autoregulatory capacity is progressively diminished with increasing severity of anemia and the LLA is shifted to the right. The first point of significant CBF reduction in the studies by Maruyama and colleagues [45], tested at $20-\mathrm{mm} \mathrm{Hg}$ increments from MAP 100 to MAP $40 \mathrm{~mm} \mathrm{Hg}$, was $40 \mathrm{~mm} \mathrm{Hg}$ with hematocrit 40\%, $60 \mathrm{~mm} \mathrm{Hg}$ with hematocrit $20 \%$, and $80 \mathrm{~mm} \mathrm{Hg}$ with hematocrit $5 \%$. These findings may have significant clinical implications for patients in the intensive care unit with stenotic neurovascular lesions or acute neurologic injuries with or without elevated ICP, where current practice is to avoid transfusion and to tolerate very low hematocrits.

\section{Effect of anemia and hypotension on $\mathrm{CBF}$ and $\mathrm{O}_{2}$ delivery}

During major surgical procedures with large and rapid blood loss, anemia and hypotension may coexist. As noted previously, anemia will superimpose underlying vasodilation on the cerebral vasculature and increase $\mathrm{CBF}$ to provide stable $\mathrm{O}_{2}$ delivery $\left(\mathrm{DO}_{2}\right)$. The ability of the vessels to further dilate with hypotension to maintain a constant $\mathrm{CBF}$ and $\mathrm{DO}_{2}$ will be diminished. Previous experiments from our institution using microspheres to measure CBF in normocapnic, normothermic pigs anesthetized with isoflurane demonstrated this concept (Fig. 6) [46]. One group of pigs was made hypotensive (euvolemic) with labetalol (MAP from $73 \mathrm{~mm} \mathrm{Hg}$ to $52 \mathrm{~mm} \mathrm{Hg}$ ) and maintained stable $\mathrm{CBF}$ and $\mathrm{DO}_{2}$. A separate group of normotensive pigs was made anemic (hematocrit from 27\% to $17 \%$ with shed blood and crystalloid replacement to maintain euvolemia) and increased CBF by approximately 50\% from baseline, resulting in stable $\mathrm{DO}_{2}$. When the conditions of both euvolemic hypotension and anemia were combined, however, CBF increased by only $8 \%$, resulting in an approximate $28 \%$ decrease in $\mathrm{DO}_{2}$. Because both anemia and hypotension require cerebral vasodilation to maintain a stable $\mathrm{DO}_{2}$, the combined effects overwhelmed the capacity of the cerebral vasculature to vasodilate sufficiently, thereby decreasing $\mathrm{DO}_{2}$. Clinical implications are that patients with severe anemia may not be able to compensate for very low blood pressure to maintain stable $\mathrm{DO}_{2}$ to the brain. These findings have implications for limiting the extremes of anemia and hypotension when attempting to minimize blood loss and/or avoid transfusion.

\section{ANESTHETIC DRUGS AND VASOACTIVE AGENTS}

This section discusses pharmacologic agents available to clinicians to help optimize cerebral perfusion, $\mathrm{CMRO}_{2}$, and brain relaxation in everyday practice. Because many of the vasoactive drugs are used to lower blood pressure, results may affected when MAP falls outside of the LLA. 


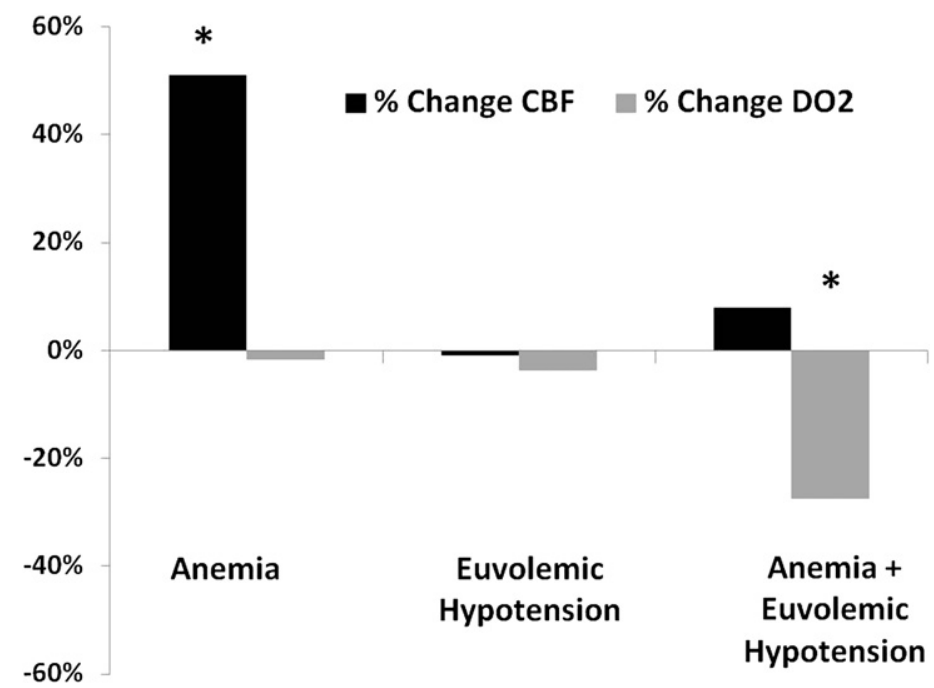

Fig. 6. The effects of anemia and hypotension on $\mathrm{CBF}$ and $\mathrm{O}_{2}$ delivery. In normocapnic, normothermic pigs anesthetized with isoflurane, anemia resulted in a dramatic increase in $\mathrm{CBF}$, which kept the $\mathrm{O}_{2}$ delivery $\left(\mathrm{DO}_{2}\right)$ to the brain stable. Similarly, severe hypotension to a MAP of approximately $50 \mathrm{~mm} \mathrm{Hg}$, resulted in stable $\mathrm{CBF}$ and stable $\mathrm{DO}_{2}$. When both conditions were combined, the $\mathrm{CBF}$ increased only $8 \%$, resulting in a $28 \%$ drop in $\mathrm{DO}_{2}\left({ }^{*} P<.05\right)$. The degree of vasodilation by the cerebral vasculature is limited and may not provide stable $\mathrm{DO}_{2}$ under extreme physiologic conditions. (Adapted from Lee LA, Deem S, Glenny RW, et al. Effects of anemia and hypotension on porcine optic nerve blood flow and oxygen delivery. Anesthesiology 2008;108(5):864.)

\section{Calcium channel blockers}

In general, calcium channel blockers (CCBs) exert their effect by inhibiting the influx of intracellular calcium via voltage-gated calcium channels on the membrane of the sarcoplasmic reticulum. This inhibition results in less intracellular calcium available, leading to a weaker contraction. CCBs can be divided into 2 categories based on the presence or absence of a dihydropyridine group. Dihydropyridine drugs include amlodipine, clevidipine, felodipine, nicardipine, nifedipine, and nimodipine, whereas nondihydropyridine drugs include diltiazem and verapamil. Calcium channels are morphologically distinct in different types of tissue, including the brain, myocardium, vascular smooth muscle, and the atrioventricular (AV) conduction system. Thus, there is intraclass variability with regard to binding selectivity of each calcium channel blocker [47].

Although most of the dihydropyridines exhibit activity in all vascular smooth muscle, decreasing cardiac afterload and providing a generalized hypotensive effect, nimodipine shows relative selectivity to the cerebral arteries at clinical doses [48]. It has been shown to provide clinical effectiveness in treating vasospasm following subarachnoid hemorrhage in humans [49]. Accordingly, a hypotensive effect is less common with nimodipine, and there is evidence 
that nimodipine slightly increases $\mathrm{CBF}$ and cerebral metabolic rate [50]. The other dihydropyridines tend to act mainly in the periphery and have no specific effect on $\mathrm{CBF}$ and cerebral metabolic rate provided mean arterial pressure is kept constant [51]. Nicardipine is one of the most commonly used intravenous CCBs in the neurosurgical patient because of its ease of titration. Clevidipine, approved by the Food and Drug Administration in 2008, is degraded by plasma esterases with a half-life of approximately 1 minute, compared with nicardipine with a half-life of 4 to 5 hours [52]. Nondihydropyridine CCBs generally act on the myocardium and the AV conduction system, but also have a small cerebral vasodilatory effect with increases in $\mathrm{CBF}$, and thus potential to increase ICP.

CCBs may also block the accumulation of intracellular calcium, which is involved in intracellular signaling processes in neuronal injury. Unfortunately, clinical trials have not shown benefit with CCBs, and some experts believe that more downstream pathways should be targeted [53].

\section{NO donors}

NO donors represent another class of drugs that can be therapeutically useful to treat acute episodes of hypertension, but these drugs have their own side effects that must be considered. All NO donors release NO in the vasculature, which then activates intracellular guanylate cyclase and increases intracellular production of cyclic guanosine monophosphate (GMP). Cyclic GMP, in turn, activates protein kinase $\mathrm{G}$ that inactivates myosin light chains causing smooth muscle relaxation and resultant vasodilation. The cerebral vasodilation caused by the NO donor drugs can result in significant increases in ICP.

Nitroprusside comes as a salt (sodium nitroprusside [SNP]) and for each molecule of NO that is released, there remains a potential 5 cyanide ions that can also be released and cause toxicity within 2 to 3 hours [54]. Studies on cerebral hemodynamics with SNP show variable results depending on study conditions but, for the most part, it has little effect on CBF in anesthetized neurosurgical patients [55]. Larger doses have been associated with loss of autoregulation, decreased CBF, and increased ICP. Recognizing the aforementioned concerns, the exceptionally short half-life of 3 to 4 minutes makes SNP useful when used on a short-term basis for acute control of blood pressure.

Nitroglycerin preferentially works as a venodilator and only affects arterial tone at higher clinical doses in a somewhat unpredictable way. Nitroglycerin has been shown to vasodilate the major cerebral vessels and to cause a decrease in CBF velocity but no change in CBF [56]. Other studies have shown a profound increase in ICP and decrease in CPP with nitroglycerin [57]. Hydralazine, also an NO donor, has its effects mainly at the level of the arterioles with vasodilation. It has similar effects in the brain and the periphery, causing cerebral vasodilation, increased CBF, and increased ICP.

Adenosine has direct vasodilating effects in the brain, and intravenous infusion will cause vasodilation of the major cerebral vessels, but no change in CBF [58]. 
It causes transient heart block (and subsequent cardiac arrest in higher doses) and is used intraoperatively to transiently stop CBF to facilitate clipping of cerebral aneurysms.

\section{Sympatholytics and sympathomimetics}

Whether or not drugs that stimulate or antagonize the body's intrinsic sympathetic nerve system affect $\mathrm{CBF}$ and autoregulation depends on the starting blood pressure, the clinical dose of the drug given, whether autoregulation is already impaired, and if the blood brain barrier is open or closed [6]. As a rule, sympatholytics and sympathomimetics do not have any major direct effects on CBF outside of their effects on systemic blood pressure, with a few exceptions that will be discussed in the following paragraphs.

Alpha-1 agonists are frequently used in patients with shock and are commonly administered to patients undergoing anesthesia. Although there is potential concern with alpha agonists causing further vasoconstriction leading to decreased CBF, there is not sufficient evidence to suggest this is the case in humans. Intracarotid infusion of norepinephrine has been shown to have no effect on CBF [6], and phenylephrine has been shown not to decrease CBF intraoperatively while patients are on cardiopulmonary bypass [59]. At clinical doses, norepinephrine does carry some beta activity, which gives it different characteristics with respect to cerebral perfusion than phenylephrine.

Alpha-2 agonists used in clinical practice are clonidine and dexmedetomidine, the latter of which shows much higher specificity to the alpha-2 adrenoreceptor. Dexmedetomidine has been shown to decrease $\mathrm{CMRO}_{2}$ and $\mathrm{CBF}[60,61]$.

Beta agonists in lower concentrations have few direct effects on the cerebral vasculature, but in higher doses can increase $\mathrm{CMRO}_{2}$ and $\mathrm{CBF}$ [62]. This effect seems to be pronounced when there is a compromise in the blood brain barrier, suggesting a direct effect of beta agonists on cerebral metabolic rate [63].

It has become clear that beta-blockers in clinical use today can be thought of in 2 categories: beta antagonists and beta inverse agonists [64]. Beta agonists cause an increase in $\mathrm{CMRO}_{2}$, and thus CBF. Beta-blockers demonstrate either no effect or a reduction in CBF [6]. Esmolol, a fast-acting beta blocker with a short half-life, has been shown to decrease anesthetic requirements, suggesting it may also decrease $\mathrm{CMRO}_{2}$ and demonstrate some inverse agonist activity in the brain $[65,66]$.

Dopamine has also been studied extensively and used mainly as a vasopressor in certain disease states, mainly to increase blood pressure in the intensive care setting in septic shock and certain types of cerebral ischemia. The medical literature currently suggests dopamine works well to increase CBF in other populations, such as preterm infants who are hypotensive [67] and patients with TBI [68], although it is not the agent of choice. In general, it has not demonstrated any direct effects on $\mathrm{CBF}$, but does cause an increase in the $\mathrm{CMRO}_{2}$ of the choroid plexus and basal ganglia $[69,70]$.

Vasopressin, although not classically considered a part of the sympathetic nervous system, has mainly been studied in situations of cardiac arrest and 
very little has been contributed on lower-dose vasopressin therapy and its effect on $\mathrm{CBF}$.

Intravenous anesthetic agents

Most intravenous anesthetic agents, with the exception of ketamine, cause a reduction in $\mathrm{CMRO}_{2}$ and $\mathrm{CBF}$, exhibiting flow-metabolism coupling. Propofol, barbiturates, and etomidate all directly cause a reduction in $\mathrm{CMRO}_{2}$ by agonizing $\gamma$-aminobutyric acid (GABA) sites, with a resultant decrease in $\mathrm{CBF}$ and ICP. Ketamine, an N-methyl-D-aspartate receptor antagonist, increases $\mathrm{CMRO}_{2}, \mathrm{CBF}$, and ICP in awake subjects [71]. When ventilation is controlled to prevent a rise in $\mathrm{PaCO}_{2}$, and a background anesthetic is also given, such as a potent volatile anesthetic or a benzodiazepine, there is no increase in $\mathrm{CMRO}_{2}, \mathrm{CBF}$, or ICP.

Benzodiazepines appear also to produce a modest reduction in $\mathrm{CBF}$, but to a lesser extent than seen with other GABA agonists. This is believed to be because of a reduction in CMR and a preservation of the coupling of CMR and CBF [5]. Opioids have shown variable responses in clinical studies and seem to depend on other anesthetics concomitantly given. In general, the effects, if present, tend to be mild and may not be clinically significant.

Volatile anesthetic agents

Volatile anesthetic agents differ from intravenous anesthetic agents in that they reduce $\mathrm{CMRO}_{2}$ in a dose-dependent fashion, but increase CBF, particularly at concentrations greater than 1 minimum alveolar concentration. Halothane has a far greater effect on CBF than isoflurane, desflurane, or sevoflurane, which all have similar effects on cerebral vasodilation. $\mathrm{NO}$ and xenon vary from the halogenated anesthetics in their effects on CBF. NO is shown to increase $\mathrm{CBF}$ with a variable effect on $\mathrm{CMRO}_{2}[72]$. When used as an adjunct to intravenous anesthetics, NO causes little change in CBF; however, when it is used in conjunction with volatile anesthetics, it causes a more dramatic increase in CBF and ICP [72]. Xenon seems to show a differential effect on CBF on gray matter and white matter, causing a decrease in the former and increase in the latter [73].

In general, when considering the pharmacologic effect of a drug on cerebral perfusion, one must consider the drug's effects on the cerebral vasculature if this varies from its effect on the systemic vasculature, the drug's effect on cerebral metabolic rate, the blood pressure before giving the drug, whether or not administration of the drug will bring the blood pressure outside or inside the cerebral autoregulatory window, and the patient's condition with respect to $\mathrm{CBF}, \mathrm{CMRO}_{2}$, and ICP (Box 5).

\section{PATIENT DISEASE STATES}

Although understanding the complex nature of $\mathrm{CBF}$ and autoregulation is important, it is essential for a clinician to understand how to apply these concepts to an individual patient, especially when these complex mechanisms 


\section{Box 5: Pharmacology key points}

- Pharmacologic mechanisms of optimizing cerebral perfusion include altering systemic arterial pressure, cerebral metabolic rate, and directly acting on cerebral arteries and arterioles.

- Drugs that can alter cerebral metabolic rate include not only anesthetics, but sympatholytics and sympathomimetics, especially when the blood brain barrier has been compromised.

- When considering an individual drug's effect on an individual patient, one must consider the patient's current condition and what other factors are already affecting $\mathrm{CBF}$, cerebral metabolic rate, and ICP.

- There is some inconsistency in the medical literature with regard to individual drug effects on $\mathrm{CBF}$, probably because of lack of control of type of anesthetic, anemia, etc. several other factors that also influence $\mathrm{CBF}$ such as (systemic $\mathrm{MAP}, \mathrm{CO}_{2}$ level, awake versus anesthetized, temperature, type of anesthetic.

are affected by patient disease, whether it be congenital abnormalities, acquired chronic disease, or acute injury (Box 6).

\section{Anatomic variants}

The most common relevant patient condition is one that will rarely be identified preoperatively, but can affect a patient's reserve for tolerating hemodynamic challenges. The anatomy of the circle of Willis varies widely in human populations, with estimates showing an intact circle of Willis in as low as $34 \%$ of the population [74-76]. There is evidence suggesting that patients with an anatomic variant of the classic circle of Willis will have different perfusion patterns and that some may be at higher risk for ischemia than others, particularly in the presence of acquired stenotic lesions [77-79].

There is significant evidence in the literature that patients with an incomplete circle of Willis, to the extent that limits collateral flow, carry a higher lifetime risk of stroke, particularly in the presence of carotid stenosis. This was best shown with prospective data from the North American Symptomatic Carotid Endarterectomy Trial (NASCET) [80], but also with retrospective data showing a nonfunctional anterior collateral pathway increased the risk of

\section{Box 6: Patient disease state key points}

- Subclinical anatomic abnormalities can make patients more susceptible to ischemic neurologic deficits perioperatively, particularly in the presence of stenotic vascular lesions.

- Certain disease states, such as hypertension, can shift the normal cerebral autoregulation curve to the right.

- TBI can impair normal autoregulation mechanisms making blood pressure control in these patients paramount to preventing secondary brain injury. 
ischemic stroke by sevenfold [81]. Additionally, the absence of posterior communicating arteries, the channel that connects the anterior circulation with the posterior circulation, was associated with border zone infarcts [82], and the fetal-type circulation has also been associated with higher rates of stroke in the medical literature with retrospective data [83]. What remains challenging about treating patients with congenital defects is they are mostly subclinical until a neurologic insult has occurred.

\section{Age effects}

There are several common diseases that frequently accompany aging, such as cerebrovascular disease, cardiovascular disease, and neurologic disease, that each modify cerebral perfusion and autoregulation in their own way, but increasing age itself seems to have very little to no effect on dynamic autoregulation [84]. Older patients do have decreased baroreceptor sensitivity and a change in position could change $\mathrm{CBF}$ values significantly, but the autoregulation curve itself seems to be unaffected [85]. There is evidence that static autoregulation appears to be affected with increasing age [86]. Elderly patients also exhibit a wider range of blood pressures diurnally, and elderly patients may be subject to regional hypoperfusion during certain times of night [87]. Additionally, overall CBF decreases from childhood to middle age, which may reflect progressive neuronal loss over time [88].

At the other spectrum of age, premature infants are also a vulnerable population, as development and maturation of the cerebral vasculature usually is not complete. In premature infants weighing less than $1500 \mathrm{~g}$, passive CBF is common, suggesting the autoregulatory mechanisms are still developing and are not working $20 \%$ of the time [89].

\section{Chronic hypertension}

Patients with chronic hypertension show structural changes in the cerebral circulation, such as vascular hypertrophy and a shift in the autoregulation curve to the right producing a higher threshold for the ULA [90]. Studies in rats provide evidence that these structural changes also provide somewhat of a protective effect on the HLA and allow chronically hypertensive patients to tolerate higher blood pressures without causing a hemorrhagic stroke. Because of these changes, acute hypotension induced with an NO donor, one of the human body's intrinsic mechanisms of vasodilation, is not tolerated as well in these patients and leads to decreased perfusion during hypotension when compared with normotensive subjects [91]. There is also evidence suggesting there are subclinical regional perfusion abnormalities in the untreated hypertensive patient [92].

Treating patients with chronic hypertension does provide benefit, as evidenced by a decreased rate of ischemic stroke $[93,94]$ and a restoration of more normal CBF dynamics $[95,96]$. Acute and chronic care of the chronically hypertensive patient should be undertaken carefully using the pharmacologic principles mentioned previously that favor mechanisms causing cerebral vasodilation in addition to peripheral vasodilation. 
Although most studies looking at the relationship of $\mathrm{CBF}$ and hypertension have been in adults, a growing prevalence of hypertension in the pediatric population urges the scientific community to examine this population more closely. It has already been shown that there is an association between hypertension and altered cerebral hemodynamics in children, potentially causing new problems in childhood not previously seen [97].

\section{Carotid stenosis/occlusion}

Carotid artery stenosis is a disease of plaque buildup associated with aging and hyperlipidemia. One main problem with the disease is that it typically remains subclinical until it has already progressed into advanced stages. Less commonly, carotid artery stenosis can develop as a complication of radiation therapy to the neck [98].

Carotid artery stenosis can lead to regional hypoperfusion if a patient's anatomy does not permit adequate collateral flow. According to analysis of the NASCET data, presence of collateral flow decreases subsequent stroke rate by as much as $60 \%$ [99]. Despite collateral flow, there is still a decrease in cerebrovascular reserve that correlates exponentially with increasing degrees of carotid stenosis [100]. The vasculature supplied by the affected carotid artery may lose its cerebrovascular reactivity [101]. Recently, investigators have found that occlusion of the external carotid artery on the same side may also increase stroke risk [102].

Although there has been much debate about when to surgically intervene with either a carotid endarterectomy or stenting, it is clear that these procedures can provide overall benefits in selected populations. Key deciding factors mainly include degree of stenosis and presence of neurologic symptoms. Procedures to alleviate carotid stenosis restore $\mathrm{CBF}$ and autoregulatory capacity to previously hypoperfused vasculature, and may improve some cognitive deficits induced by carotid artery stenosis $[103,104]$.

There has been immense interest in determining the best course of treatment for carotid artery stenosis, whether it be placement of a carotid artery stent (CAS) or carotid endarterectomy (CEA). A randomized controlled trial of CAS versus CEA ("CREST" trial) demonstrated no statistically significant difference in the primary outcome (determined as combined rates of periprocedural mortality, myocardial infarction, and stroke, and ipsilateral stroke over 4 years) between the 2 groups; however, the rate of stroke $(4.1 \%$ vs $2.3 \%, P=.012)$ was higher with CAS, whereas the rate of myocardial infarction was slightly higher with CEA $(1.1 \%$ vs $2.3 \%, P=.032$ ) [105]. Additionally, outcomes for patients younger than 70 years were better with CAS, and outcomes were better with CEA for patients older than 70 years or with symptomatic stenosis. Since publication of the CREST trial and some meta-analyses following it, the American Heart Association and American Stroke Association published collaborative recommendations indicating carotid endarterectomy for symptomatic patients and for older patients, and carotid artery stenting for certain asymptomatic patients of younger age [106].

Cerebral hyperperfusion syndrome (CHS) can occur after a symptom-free interval postoperatively in $1 \%$ to $3 \%$ of patients, and is thought to be caused 
by an impaired autoregulatory mechanism in the affected hypoperfused tissue that takes time to recover after normal flow is restored [107-109]. It can occur up to 4 weeks after the original procedure and is associated with a symptomatic period of nausea, vomiting, headache, or other neurologic deficits. If untreated, it may lead to ipsilateral hemorrhagic stroke and death in up to $40 \%$ of patients [107]. Methods recently proposed to help prevent this complication, in addition to strict perioperative blood pressure control, include staged angioplasty, perioperative transcranial Doppler measurements, and calculating cerebral circulation time.

\section{Traumatic brain injury}

TBI is a substantial public health problem with approximately 1.7 million TBIs every year in the United States [110]. Although the most effective treatment for this disease is prevention, most medical intervention is focused around preventing secondary injury, which can affect all systems of the body. Understanding how cerebral perfusion and autoregulation can be altered in these patients is paramount to preventing secondary brain injury.

In addition to preventing common sequelae of TBI that negatively affect the brain, such as hypotension, hypoxia, hypoglycemia, hyperthermia, hypocapnia, and intracranial hypertension, the main focus of treatment of TBI is to continuously deliver oxygen to the brain, which is done by optimizing CPP, as autoregulation is frequently impaired even with mild head injuries. There have been several new methods recently published determining methods of tailoring therapy to each individual patient's "ideal perfusion pressure" by analyzing ICP waveforms in addition to arterial pressure waveforms, respiratory oscillations, transcranial Doppler, and, in some cases, short-term moderate hypocapnia [111-113]. In addition, optimizing and measuring neuronal tissue oxygenation may improve neurologic outcome [114].

In pediatric patients in whom normal CPP values vary widely depending on age, recent research has focused on the pressure reactivity index to determine the ideal CPP in children. It is being used to correlate mortality with pressures below the ideal pressure, and disability with pressures above the ideal pressure [115]. It may prove to be an important therapeutic target, as low CBF and poor autoregulatory capacity are highly correlated with poor outcomes [116].

\section{EFFECTS OF POSITIONING ON CEREBRAL PERFUSION}

\section{Surgery in the beach chair position}

A controversial topic surrounding cerebral perfusion that has arisen in the past several years is anesthetic management of blood pressure in the beach chair position in patients receiving general anesthesia. This concern arose after a series of 4 cases was reported in 2005, detailing severe brain damage in the beach chair position for shoulder surgery [117]. These devastating injuries were thought to be the result of both surgical requests for deliberate hypotension and lack of correction of the blood pressure in the sitting position for height from the noninvasive blood pressure (NIBP) cuff to the external 
auditory meatus (EAC). Although measuring blood pressure at the EAC has always been standard practice in neuroanesthesia, this concept did not effectively transmit into other surgical arenas, particularly one known for relatively minor outpatient procedures.

Correcting the blood pressure to account for height difference between the site of measurement and the brain addresses the hydrostatic gradient from the effect of gravity (Fig. 7). For every centimeter of height difference between the NIBP cuff and the EAC, $0.77 \mathrm{~mm} \mathrm{Hg}$ should be subtracted from the NIBP reading on the arm or leg to approximate the true MAP at the EAC (or for every inch difference, $2 \mathrm{~mm} \mathrm{Hg}$ subtracted). It is based on the theory that the cerebral circulation acts similar to a "waterfall" system subject to gravitational effects, rather than as a closed siphon system that operates independent of gravity. Since this case series and subsequent controversy, an experiment in anesthetized giraffes demonstrated that the CBF was controlled by arterial pressure without contribution from a siphon mechanism [118]. Admittedly, the waterfall concept does not fully explain cerebral circulation in instances of zero gravity; yet it appears to account for clinically relevant situations.

Many clinical studies have also been performed since this case series was published, including McCulloch and colleagues' [119] study showing that MAP at the EAC decreased $47 \% \pm 7 \%$ in the sitting position at $45^{\circ}$ with an associated $22 \% \pm 7 \%$ decrease in the CBF velocity in the middle cerebral artery. Systolic blood pressure was $96 \pm 10 \mathrm{~mm} \mathrm{Hg}$ by noninvasive measurement on the arm. Another study, by Jeong and colleagues [120], demonstrated jugular desaturation to less than $50 \%$ for at least 5 minutes in $41 \%$ of patients in the beach chair position under general anesthesia, with a significantly higher proportion of desaturations in the propofol/remifentanil group (56\%) compared with the sevoflurane $/ 50 \%$ NO group $(21 \%, P=.008)$. Jugular saturation in the sitting position in the propofol/remifentanil group decreased by $22 \% \pm 12 \%$ from supine baseline, and by $14 \% \pm 12 \%$ in the sevoflurane $/ 50 \%$ NO group.
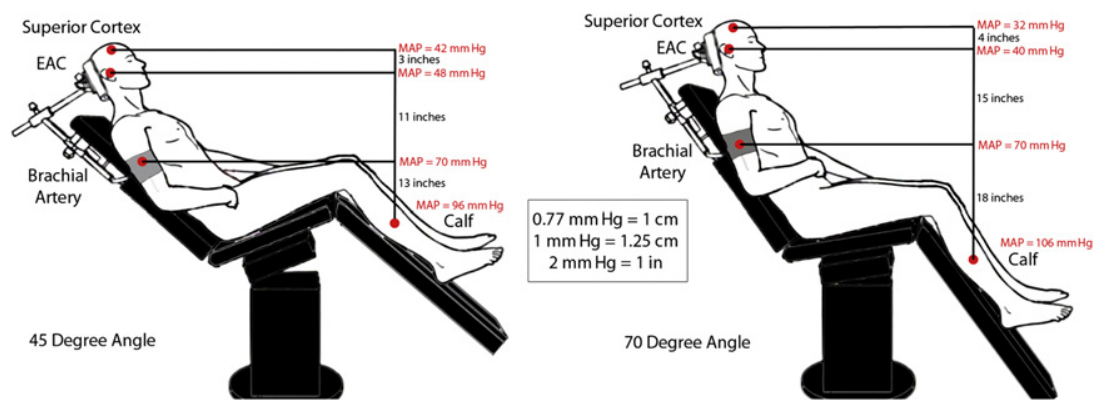

Fig. 7. Beach chair position shown at $45^{\circ}$ angle on left, and $70^{\circ}$ angle on right. MAP calculations shown when correcting for the hydrostatic gradient from the site of the noninvasive blood pressure measurement to the brain. 
Jugular desaturation was also related to MAP lower than $50 \mathrm{~mm} \mathrm{Hg}$ measured at the EAC.

One practice that may further place these patients at risk for cerebral ischemia is the frequent surgical request for deliberate hypotension, particularly when it is facilitated with drugs that do not cause cerebral vasodilation. In addition to the need to correct for the hydrostatic gradient in these cases, we previously discussed how hypotension caused by low cardiac output (ie, hemorrhage, or in this situation head up position under general anesthesia) has been shown to raise the LLA compared with hypotension induced by vasoactive agents. Other issues that may predispose to inadequate cerebral perfusion are the wide variability in the LLA among individuals, the very high incidence of incomplete circle of Willis anatomy in the general population, specialized headrests and head positions that may distort the vascular anatomy in the head and neck, and previously asymptomatic stenotic vascular lesions. Despite having the "deck" stacked against adequate cerebral perfusion in these procedures, the incidence of these devastating injuries appears to be low, although no reliable mechanism for reporting exists. These procedures are typically brief, lasting only a few hours; yet, one professional liability company recently noted at least 9 lawsuits associated with neurological injuries sustained in the beach chair position with large settlement payments related to the issue of hypotension and uncorrected blood pressure in the sitting position [121].

\section{Venous effect on CPP: ischemic optic neuropathy associated with prolonged prone or steep trendelenburg position}

Since the late 1990s, the perioperative complication of ischemic optic neuropathy after prolonged prone spine surgery has received significant attention from anesthesiologists, spine surgeons, and neuro-ophthalmologists. In early 2012, a multicenter case-control study using 80 cases of ischemic optic neuropathy (ION) from the American Society of Anesthesiologists Postoperative Visual Loss Registry and comparing them with 315 controls from 17 centers across North America identified 6 independent risk factors for ION after prone spine surgery [122]. These 6 risk factors are male sex, obesity, use of a Wilson frame, prolonged duration of anesthesia (ie, surgery), increased blood loss, and decreased administration of colloid in the nonblood fluid administration. With the exception of male sex, these risk factors all support the theory that this complication is related to elevated venous pressure in the prone position with subsequent interstitial fluid accumulation and compromise of the vascular supply to the optic nerve. Although no animal data have yet supported this theoretical pathophysiologic mechanism, its occurrence in these 2 procedures with greatly elevated venous pressure, and in bilateral radical head and neck operations is consistent with this theory. This complication is unique because it highlights the importance of outflow pressure in CPP in non-neurosurgical procedures. Whether or not increasing the MAP in these cases is beneficial has not been tested, as it is not clear that using excessive inflow pressure will improve perfusion once the venous outflow problem has developed. Interestingly, these 
patients often do not have associated cerebral injuries. Currently, there is no reliable intraoperative monitor for detecting optic nerve ischemia or dysfunction intraoperatively during general anesthesia.

\section{INTRAOPERATIVE MONITORS FOR ASSESSMENT OF CBF AND CEREBRAL ISCHEMIA}

For the general anesthesiologist, use of equipment such as a transcranial Doppler, although useful, is not practical, and can require significant setup time. For high-risk cases, such as CEA, its benefit may be enormous, and obtaining a vascular technologist to measure CBF velocity intraoperatively is recommended when available. Similarly, 16-channel EEG is not likely to be used on an outpatient procedure, but may prove valuable in high-risk procedures. Alternatively, the widespread use of the bispectral index, which is a processed EEG, can provide crude assessments of frontal brain activity, and may give some indication of global adequacy of perfusion. Near infrared spectroscopy is currently widely used in research, but its reliance on trends and lack of absolute values for ischemia make its validity unclear, particularly in adults in whom skull thickness is much greater than in neonates. For anesthesiologists who work at major neurosurgical or neurotrauma centers, familiarity with ICP monitors is essential, and use of surgically placed brain tissue oxygen monitors and autoregulation testing may also be useful for guiding anesthetic management. The expansion of intraoperative evoked potential monitoring to detect cerebral ischemia, as well as injury to the spinal cord and peripheral nerves, may significantly alter anesthetic management, and can provide early warnings of injury and allow modification of surgical and anesthetic care.

The concepts discussed in this updated review should help anesthesiologists optimize management of cerebral perfusion in routine outpatient and inpatient procedures, high-risk neurosurgical and non-neurosurgical procedures, and in high-risk patients with preexisting cerebrovascular disease.

\section{References}

[1] Mashour GA, Shanks AM, Kheterpal S. Perioperative stroke and associated mortality after noncardiac, nonneurologic surgery. Anesthesiology $2011 ; 114(6)$ :1289-96.

[2] Devereaux PJ, Yang H, Yusuf S, et al. Effects of extended-release metoprolol succinate in patients undergoing non-cardiac surgery (POISE trial): a randomised controlled trial. Lancet 2008;371 (9627): 1839-47.

[3] Biiker JB, Persoon S, Peelen LM, et al. Intraoperative hypotension and perioperative ischemic stroke after general surgery: a nested case-control study. Anesthesiology 2012;116(3):658-64.

[4] Ng JL, Chan MT, Gelb AW. Perioperative stroke in noncardiac, nonneurosurgical surgery. Anesthesiology $2011 ; 115(4): 879-90$.

[5] Cottrell JE, Young WL. Cottrell's neuroanesthesia. 5th edition. St. Louis (MO); London: Mosby; 2009.

[6] Miller RD. Miller's anesthesia. 7th edition. Philadelphia: Churchhill Livingstone Elsevier; 2010.

[7] Bell BA. A history of the study of the cerebral circulation and the measurement of cerebral blood flow. Neurosurgery 1984;14(2):238-46. 
[8] Jakovcevic D, Harder DR. Role of astrocytes in matching blood flow to neuronal activity. Curr Top Dev Biol 2007;79:75-97.

[9] Gordon GR, Howarth C, MacVicar BA. Bidirectional control of arteriole diameter by astrocytes. Exp Physiol 2011 ;96(4):393-9.

[10] lliff JJ, Wang R, Zeldin DC, et al. Epoxyeicosanoids as mediators of neurogenic vasodilation in cerebral vessels. Am J Physiol Heart Circ Physiol 2009;296(5): H1352-63.

[1 1] Kety SS, Schmidt CF. The effects of altered arterial tensions of carbon dioxide and oxygen on cerebral blood flow and cerebral oxygen consumption of normal young men. J Clin Invest 1948;27(4):484-92.

[12] Iliff LD, Zilkha E, Du Boulay GH, et al. Cerebrovascular carbon dioxide reactivity and conductance in patients awake and under general anesthesia. Neurology 1976;26(9): 835-8.

[13] Lindaver U, Vogt J, Schuh-Hofer S, et al. Cerebrovascular vasodilation to extraluminal acidosis occurs via combined activation of ATP-sensitive and $\mathrm{Ca} 2+$-activated potassium channels. J Cereb Blood Flow Metab 2003;23(10):1227-38.

[14] Wagerle LC, Degiulio PA. Indomethacin-sensitive CO2 reactivity of cerebral arterioles is restored by vasodilator prostaglandin. Am J Phys 1994;266(4 Pt 2):H1332-8.

[15] Gupta AK, Menon DK, Czosnyka M, et al. Thresholds for hypoxic cerebral vasodilation in volunteers. Anesth Analg 1997;85(4):817-20.

[16] Borgstrom L, Johannsson H, Siesjo BK. The relationship between arterial po2 and cerebral blood flow in hypoxic hypoxia. Acta Physiol Scand 1975;93(3):423-32.

[17] Van Mil AH, Spilt A, Van Buchem MA, et al. Nitric oxide mediates hypoxia-induced cerebral vasodilation in humans. J Appl Phys 2002;92(3):962-6.

[18] Todd MM, Farrell S, Wu B. Cerebral blood flow during hypoxemia and hemodilution in rabbits: different roles for nitric oxide? J Cereb Blood Flow Metab 1997;17(12): 1319-25.

[19] Vavilala MS, Lee LA, Morris GP, et al. Cerebral autoregulation before and after blood transfusion in a child. J Neurosurg Anesthesiol 2001;13(3):233-6.

[20] Tomiyama Y, Jansen K, Brian JE Jr, et al. Hemodilution, cerebral O2 delivery, and cerebral blood flow: a study using hyperbaric oxygenation. Am J Phys 1999;276(4 P+2):H1 190-6.

[21] Clifton GL, Miller ET, Choi SC, et al. Lack of effect of induction of hypothermia after acute brain injury. N Engl J Med 2001;344(8):556-63.

[22] Todd $M M$, Hindman BJ, Clarke WR, et al. Mild intraoperative hypothermia during surgery for intracranial aneurysm. N Engl J Med 2005;352(2):135-45.

[23] Arrich J, Holzer M, Havel C, et al. Hypothermia for neuroprotection in adults after cardiopulmonary resuscitation. Cochrane Database Syst Rev 2012;9:CD004128.

[24] Cremer OL, Diephuis JC, van Soest H, et al. Cerebral oxygen extraction and autoregulation during extracorporeal whole body hyperthermia in humans. Anesthesiology 2004;100(5):1101-7.

[25] Fan JL, Cotter JD, Lucas RA, et al. Human cardiorespiratory and cerebrovascular function during severe passive hyperthermia: effects of mild hypohydration. J Appl Phys 2008; 105(2):433-45.

[26] Peterson EC, Wang Z, Britz G. Regulation of cerebral blood flow. Int J Vasc Med $2011 ; 2011: 823525$.

[27] Cassaglia PA, Griffiths RI, Walker AM. Sympathetic nerve activity in the superior cervical ganglia increases in response to imposed increases in arterial pressure. Am J Physiol Regul Integr Comp Physiol 2008;294(4):R 1255-61.

[28] Hernandez M, Raichle ME, Stone HL. The role of the sympathetic nervous system in cerebral blood flow autoregulation. Eur Neurol 1971;6(1):175-9.

[29] Heistad DD. Summary of symposium on cerebral blood flow: effect of nerves and neurotransmitters. Cardiovascular center, University of lowa, lowa City, lowa, June 16-18, 1981. J Cereb Blood Flow Metab 1981;1 (4):447-50. 
[30] D'Alecy LG. Relation between sympathetic cerebral vasoconstriction and CSF pressure. Eur Neurol 1971;6(1):180-4.

[31] Fitch W, Ferguson GG, Sengupta D, et al. Autoregulation of cerebral blood flow during controlled hypotension in baboons. J Neurol Neurosurg Psychiatr 1976;39(10):1014-22.

[32] Jones SC, Easley KA, Radinsky CR, et al. Nitric oxide synthase inhibition depresses the height of the cerebral blood flow-pressure autoregulation curve during moderate hypotension. J Cereb Blood Flow Metab 2003;23(9): 1085-95.

[33] Finnerty FA Jr, Witkin L, Fazekas JF. Cerebral hemodynamics during cerebral ischemia induced by acute hypotension. J Clin Invest 1954;33(9):1227-32.

[34] Sharbrough FW, Messick JM Jr, Sundt TM Jr. Correlation of continuous electroencephalograms with cerebral blood flow measurements during carotid endarterectomy. Stroke 1973;4(4):674-83.

[35] Branston NM, Ladds A, Symon L, et al. Comparison of the effects of ischaemia on early components of the somatosensory evoked potential in brainstem, thalamus, and cerebral cortex. J Cereb Blood Flow Metab 1984;4(1):68-81.

[36] Leech PJ, Miller JD, Fitch W, et al. Cerebral blood flow, internal carotid artery pressure, and the EEG as a guide to the safety of carotid ligation. J Neurol Neurosurg Psychiatr 1974;37(7):854-62.

[37] Astrup J, Symon L, Branston NM, et al. Cortical evoked potential and extracellular K+ and $\mathrm{H}+$ at critical levels of brain ischemia. Stroke 1977;8(1):51-7.

[38] Drummond JC. The lower limit of autoregulation: time to revise our thinking? Anesthesiology 1997;86(6):1431-3.

[39] Strandgaard S. Autoregulation of cerebral blood flow in hypertensive patients. The modifying influence of prolonged antihypertensive treatment on the tolerance to acute, druginduced hypotension. Circulation 1976;53(4):720-7.

[40] Sharrock NE, Mineo R, Urquhart B. Hemodynamic response to low-dose epinephrine infusion during hypotensive epidural anesthesia for total hip replacement. Reg Anesth 1990; 15(6):295-9.

[41] Aaslid R, Lindegaard KF, Sorteberg W, et al. Cerebral Autoregulation Dynamics in Humans. Stroke 1989;20(1):45-52.

[42] McCulloch TJ, Visco E, Lam AM. Graded hypercapnia and cerebral autoregulation during sevoflurane or propofol anesthesia. Anesthesiology 2000;93(5): 1205-9.

[43] Harper AM, Glass HI. Effect of alterations in the arterial carbon dioxide tension on the blood flow through the cerebral cortex at normal and low arterial blood pressures. J Neurol Neurosurg Psychiatr 1965;28(5):449-52.

[44] Ouchi T, Ochiai R, Takeda J, et al. Combined effects of propofol and mild hypothermia on cerebral metabolism and blood flow in rhesus monkey: a positron emission tomography study. J Anesth 2006;20(3):208-14.

[45] Maruyama M, Shimoji K, Ichikawa T, et al. The effects of extreme hemodilutions on the autoregulation of cerebral blood flow, electroencephalogram and cerebral metabolic rate of oxygen in the dog. Stroke 1985; 16(4):675-9.

[46] Lee LA, Deem S, Glenny RW, et al. Effects of anemia and hypotension on porcine optic nerve blood flow and oxygen delivery. Anesthesiology 2008; 108(5):864-72.

[47] Mizgala HF. The calcium channel blockers: pharmacology and clinical applications. Can Anaesth Soc J 1983;30(3 Pt 2):S5-10.

[48] Steen PA, Newberg LA, Milde JH, et al. Nimodipine improves cerebral blood flow and neurologic recovery after complete cerebral ischemia in the dog. J Cereb Blood Flow Metab 1983;3(1):38-43.

[49] Toni $D$, Frontoni $M$, Argentino $C$, et al. Update on calcium antagonists in cerebrovascular diseases. J Cardiovasc Pharmacol 1991;18(Suppl 8):S10-4.

[50] Sahlin C, Delgado T, Owman C, et al. Changes in cerebral blood flow and metabolism following intraarterial or local administration of nimodipine, before and after experimental subarachnoid hemorrhage in baboons. Stroke 1986;17(2):220-4. 
[51] Alborch E, Salom JB, Torregrosa G. Calcium channels in cerebral arteries. Pharmacol Ther $1995 ; 68(1): 1-34$.

[52] Frank Peacock W, Varon J, Ebrahimi R, et al. Clevidipine for severe hypertension in patients with renal dysfunction: a VELOCITY trial analysis. Blood Press Suppl 2011;1: 20-5.

[53] Szydlowska K, Tymianski M. Calcium, ischemia and excitotoxicity. Cell Calcium 2010;47(2):122-9.

[54] Marik PE, Varon J. Perioperative hypertension: a review of current and emerging therapeutic agents. J Clin Anesth 2009;21 (3):220-9.

[55] Henriksen L, Thorshauge C, Harmsen A, et al. Controlled hypotension with sodium nitroprusside: effects on cerebral blood flow and cerebral venous blood gases in patients operated for cerebral aneurysms. Acta Anaesthesiol Scand 1983;27(1):62-7.

[56] Schoonman GG, van der Grond J, Kortmann C, et al. Migraine headache is not associated with cerebral or meningeal vasodilatation-a 3T magnetic resonance angiography study. Brain 2008; 131 (Pt 8):2192-200.

[57] Cottrell JE, Gupta B, Rappaport H, et al. Intracranial pressure during nitroglycerin-induced hypotension. J Neurosurg 1980;53(3):309-11.

[58] Hussain R, Tsuchida T, Kudo T, et al. Vasodilatory effect of adenosine triphosphate does not change cerebral blood flow: a PET study with (15)O-water. Ann Nucl Med 2009;23(8): 717-23.

[59] Rogers AT, Stump DA, Gravlee GP, et al. Response of cerebral blood flow to phenylephrine infusion during hypothermic cardiopulmonary bypass: influence of $\mathrm{PaCO} 2$ management. Anesthesiology 1988;69(4):547-51.

[60] Prielipp RC, Wall MH, Tobin JR, et al. Dexmedetomidine-induced sedation in volunteers decreases regional and global cerebral blood flow. Anesth Analg 2002;95(4):1052-9.

[61] Drummond JC, Dao AV, Roth DM, et al. Effect of dexmedetomidine on cerebral blood flow velocity, cerebral metabolic rate, and carbon dioxide response in normal humans. Anesthesiology 2008; 108(2):225-32.

[62] Bryan RM Jr. Cerebral blood flow and energy metabolism during stress. Am J Phys 1990;259(2 Pt 2):H269-80.

[63] King BD, Sokoloff L, Wechsler RL. The effects of l-epinephrine and I-norepinephrine upon cerebral circulation and metabolism in man. J Clin Invest 1952;31 (3):273-9.

[64] Ameredes BT. Beta-2-receptor regulation of immunomodulatory proteins in airway smooth muscle. Front Biosci (Schol Ed) 2011;3:643-54.

[65] Johansen JW, Schneider G, Windsor AM, et al. Esmolol potentiates reduction of minimum alveolar isoflurane concentration by alfentanil. Anesth Analg 1998;87(3):671-6.

[66] Johansen JW, Flaishon R, Sebel PS. Esmolol reduces anesthetic requirement for skin incision during propofol/nitrous oxide/morphine anesthesia. Anesthesiology 1997;86(2):364-71.

[67] Sassano-Higgins S, Friedlich P, Seri I. A meta-analysis of dopamine use in hypotensive preterm infants: blood pressure and cerebral hemodynamics. J Perinatol 2011;31(10): 647-55.

[68] Pfister D, Strebel SP, Steiner LA. Effects of catecholamines on cerebral blood vessels in patients with traumatic brain injury. Eur J Anaesthesiol Suppl 2008;42:98-103.

[69] Bandres J, Yao L, Nemoto EM, et al. Effects of dobutamine and dopamine on whole brain blood flow and metabolism in unanesthetized monkeys. J Neurosurg Anesthesiol 1992;4(4):250-6.

[70] Townsend JB, Ziedonis DM, Bryan RM, et al. Choroid plexus blood flow: evidence for dopaminergic influence. Brain Res 1984;290(1):165-9.

[71] Langsjo JW, Maksimow A, Salmi E, et al. S-ketamine anesthesia increases cerebral blood flow in excess of the metabolic needs in humans. Anesthesiology 2005; 103(2):258-68.

[72] Algotsson L, Messeter K, Rosen I, et al. Effects of nitrous oxide on cerebral haemodynamics and metabolism during isoflurane anaesthesia in man. Acta Anaesthesiol Scand $1992 ; 36(1): 46-52$. 
[73] Laitio RM, Kaisti KK, Laangsjo JW, et al. Effects of xenon anesthesia on cerebral blood flow in humans: a positron emission tomography study. Anesthesiology 2007;106(6): 1128-33.

[74] McCullough AW. Some anomalies of the cerebral circle (of Willis) and related vessels. The Anatomical Record 1962;142:537-43.

[75] Macchi C, Catini C, Federico C, et al. Magnetic resonance angiographic evaluation of circulus arteriosus cerebri (circle of Willis): a morphologic study in 100 human healthy subjects. Ital J Anat Embryol 1996;101(2):115-23.

[76] Kapoor K, Singh B, Dewan LI. Variations in the configuration of the circle of Willis. Anat Sci Int 2008;83(2):96-106.

[77] Battacharii SK, Hutchinson EC, McCall AJ. The Circle of Willis-the incidence of developmental abnormalities in normal and infarcted brains. Brain 1967;90(4):747-58.

[78] van Raamt AF, Mali WP, van Laar PJ, et al. The fetal variant of the circle of Willis and its influence on the cerebral collateral circulation. Cerebrovasc Dis 2006;22(4):217-24.

[79] Drummond JC, Lee RR, Howell JP Jr. Case report: focal cerebral ischemia after surgery in the "beach chair" position: the role of a congenital variation of circle of Willis anatomy. Anesth Analg 2012;114(6):1301-4.

[80] Henderson RD, Eliasziw M, Fox AN, et al. Angiographically defined collateral circulation and risk of stroke in patients with severe carotid artery stenosis. North American Symptomatic Carotid Endarterectomy Trial (NASCET) Group. Stroke 2000;31 (1):128-32.

[81] Hoksbergen AW, Legemate DA, Csiba L, et al. Absent collateral function of the circle of Willis as risk factor for ischemic stroke. Cerebrovasc Dis 2003;16(3):191-8.

[82] Schomer DF, Marks MP, Steinberg GK, et al. The anatomy of the posterior communicating artery as a risk factor for ischemic cerebral infarction. NEngl J Med 1994;330(22): 1565-70.

[83] Kameyama M, Okinaka SH. Collateral circulation of the brain with special reference to atherosclerosis of the major cervical and cerebral arteries. Neurology 1963;13:279-86.

[84] Carey BJ, Eames PJ, Blake M, et al. Dynamic cerebral autoregulation is unaffected by aging. Stroke 2000;31(12):2895-900.

[85] Carey BJ, Panerai RB, Potter JF. Effect of aging on dynamic cerebral autoregulation during head-up tilt. Stroke 2003;34(8):1871-5.

[86] Eames PJ, Blake M, Panerai RB, et al. Cerebral autoregulation indices are unimpaired by hypertension in middle aged and older people. Am J Hypertens 2003; 16(9 Pt 1):746-53.

[87] Schmieder K, Moller F, Engelhardt M, et al. Dynamic cerebral autoregulation in patients with ruptured and unruptured aneurysms after induction of general anesthesia. Zentralbl Neurochir 2006;67(2):81-7.

[88] Meyer JS, Terayama Y, Takashima S. Cerebral circulation in the elderly. Cerebrovasc Brain Metab Rev 1993;5(2): 122-46.

[89] Soul JS, Hammer PE, Tsuji M, et al. Fluctuating pressure-passivity is common in the cerebral circulation of sick premature infants. Pediatr Res 2007;61(4):467-73.

[90] Faraci FM, Baumbach GL, Heistad DD. Cerebral circulation: humoral regulation and effects of chronic hypertension. J Am Soc Nephrol 1990; 1 (1):53-7.

[91] Hoffman WE, Albrecht RF, Miletich DJ. Cerebrovascular and metabolic effects of SNPinduced hypotension in young and aged hypertensive rats. Anesthesiology 1982;56(6): 427-30.

[92] Nobili F, Rodriguez G, Marenco S, et al. Regional cerebral blood flow in chronic hypertension. A correlative study. Stroke 1993;24(8):1 148-53.

[93] Collins R, Peto R, MacMahon S, et al. Blood pressure, stroke, and coronary heart disease. Part 2, Short-term reductions in blood pressure: overview of randomised drug trials in their epidemiological context. Lancet 1990;335(8693):827-38.

[94] Prevention of stroke by antihypertensive drug treatment in older persons with isolated systolic hypertension. Final results of the Systolic Hypertension in the Elderly Program (SHEP). SHEP Cooperative Research Group. JAMA 1991;265(24):3255-64. 
[95] Strandgaard S, Paulson OB. Cerebral blood flow in untreated and treated hypertension. Neth J Med 1995;47(4): 180-4.

[96] Shinyama $H$, Nagai $H$, Kawamura T, et al. Effects of long-term treatment with the calcium antagonist AEO047 on cerebrovascular autoregulation and hypertrophy in spontaneously hypertensive rats. J Cardiovasc Pharmacol 1997;30(5):616-22.

[97] Wong L, Kupferman JC, Prohovnik I, et al. Hypertension impairs vascular reactivity in the pediatric brain. Stroke 2011;42(7):1834-8.

[98] Chang YJ, Chang TC, Lee TH, et al. Predictors of carotid artery stenosis after radiotherapy for head and neck cancers. J Vasc Surg 2009;50(2):280-5.

[99] Tomura N, Otani T, Koga M, et al. Correlation between severity of carotid stenosis and vascular reserve measured by acetazolamide brain perfusion single photon emission computed tomography. J Stroke Cerebrovasc Dis 2011 . [Epub ahead of print].

[100] Jongen $L M$, van der Worp HB, Waaijer A, et al. Interrelation between the degree of carotid stenosis, collateral circulation and cerebral perfusion. Cerebrovasc Dis 2010;30(3): 277-84.

[101] Bokkers RP, van Osch M, Klijn CJ, et al. Cerebrovascular reactivity within perfusion territories in patients with an internal carotid artery occlusion. J Neurol Neurosurg Psychiatr $2011 ; 82(9): 1011-6$.

[102] Dalainas I, Avgerinos ED, Daskalopoulos ME, et al. The critical role of the external carotid artery in cerebral perfusion of patients with total occlusion of the internal carotid artery. Int Angiol 2012;31(1):16-21.

[103] Tang SC, Huang YW, Shieh JS, et al. Dynamic cerebral autoregulation in carotid stenosis before and after carotid stenting. J Vasc Surg 2008;48(1):88-92.

[104] Duan W, Chun-Qing Z, Zheng J, et al. Relief of carotid stenosis improves impaired cognition in a rat model of chronic cerebral hypoperfusion. Acta Neurobiol Exp 2011;71(2): 233-43.

[105] Brott TG, Hobson RW 2nd, Howard G, et al. Stenting versus endarterectomy for treatment of carotid-artery stenosis. N Engl J Med 2010;363(1):11-23.

[106] Furie KL, Kasner SE, Adams RJ, et al. Guidelines for the prevention of stroke in patients with stroke or transient ischemic attack: a guideline for healthcare professionals from the American Heart Association/American Stroke Association. Stroke 201 1;42(1):227-76.

[107] van Mook WN, Rennenberg RJ, Schurink GW, et al. Cerebral hyperperfusion syndrome. Lancet Neurol 2005;4(12):877-88.

[108] Torgovnick J, Sethi N, Arsura E. Cerebral hyperperfusion syndrome occurring three weeks after carotid endarterectomy. Rev Bras Cir Cardiovasc 2007;22(1):1 16-8 [ in English, Portuguese].

[109] Dalman JE, Beenakkers IC, Moll FL, et al. Transcranial Doppler monitoring during carotid endarterectomy helps to identify patients at risk of postoperative hyperperfusion. Eur J Vasc Endovasc Surg 1999; 18(3):222-7.

[1 10] Coronado VG, Xu L, Basavaraju SV, et al. Surveillance for traumatic brain injury-related deaths-United States, 1997-2007. MMWR Surveill Summ 201 1;60(5):1-32.

[ $\left[\begin{array}{lll}1 & 1 & 1\end{array}\right]$ Haubrich C, Steiner L, Kasprowicz M, et al. Short-term moderate hypocapnia augments detection of optimal cerebral perfusion pressure. J Neurotrauma $2011 ; 28(7): 1133-7$.

[1 12] Budohoski KP, Czosnyka M, de Riva N, et al. The relationship between cerebral blood flow autoregulation and cerebrovascular pressure reactivity after traumatic brain injury. Neurosurgery $2012 ; 71(3): 652-61$.

[113] Lewis PM, Smielewski P, Rosenfeld JV, et al. Assessment of cerebral autoregulation from respiratory oscillations in ventilated patients after traumatic brain injury. Acta Neurochir Suppl 2012;114:141-6.

[114] Beynon C, Kiening KL, Orakcioglu B, et al. Brain tissue oxygen monitoring and hyperoxic treatment in patients with traumatic brain injury. J Neurotrauma 2012;29(12):2109-23.

[115] Brady KM, Shaffner DH, Lee JK, et al. Continuous monitoring of cerebrovascular pressure reactivity after traumatic brain injury in children. Pediatrics 2009;124(6):e1205-12. 
[1 16] Adelson PD, Srinivas R, Chang Y, et al. Cerebrovascular response in children following severe traumatic brain injury. Childs Nerv Syst 2011 ;27(9): 1465-76.

[117] Pohl A, Cullen DJ. Cerebral ischemia during shoulder surgery in the upright position: a case series. J Clin Anesth 2005;17(6):463-9.

[1 18] Brondum E, Hasenkam JM, Secher NH, et al. Jugular venous pooling during lowering of the head affects blood pressure of the anesthetized giraffe. Am J Physiol Regul Integr Comp Physiol Oct 2009;297(4):R1058-65.

[1 19] McCulloch TJ, Liyanagama K, Petchell J. Relative hypotension in the beach-chair position: effects on middle cerebral artery blood velocity. Anaesth Intensive Care 2010;38(3): 486-91.

[120] Jeong $\mathrm{H}$, Lee $\mathrm{SH}$, Jan EA, et al. Haemodynamics and cerebral oxygenation during arthroscopic shoulder surgery in beach chair position under general anaesthesia. Acta Anaesthesiol Scand 2012;56(7):872-9.

[121] Sanford S. No day at the beach: catastrophic injuries in head-up position surgeries. Anesthesia the Law: A Risk Management Newsletter 2012;33:1-5.

[122] The Postoperative Visual Loss Study Group. Risk factors associated with ischemic optic neuropathy after spine surgery. Anesthesiology 2012;116(1):15-24. 